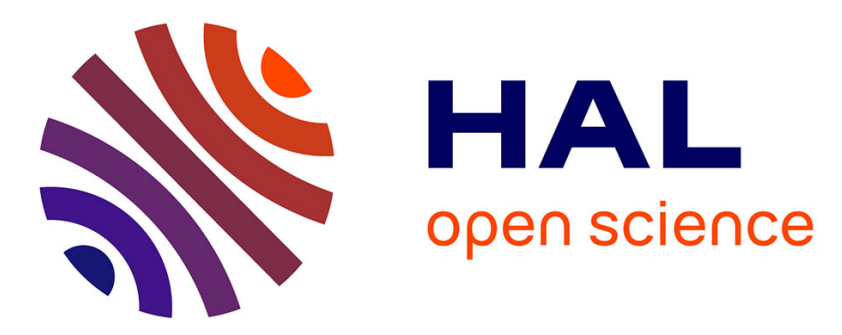

\title{
Selective Separation of Cobalt and Nickel using a Stable Supported Ionic Liquid Membrane
}

Guillaume Zante, Maria Yu Boltoeva, Abderrazak Masmoudi, Rémi Barillon, Dominique Trébouet

\section{To cite this version:}

Guillaume Zante, Maria Yu Boltoeva, Abderrazak Masmoudi, Rémi Barillon, Dominique Trébouet. Selective Separation of Cobalt and Nickel using a Stable Supported Ionic Liquid Membrane. Separation and Purification Technology, 2020, 252, pp.117477. 10.1016/j.seppur.2020.117477 . hal-03419681

\section{HAL Id: hal-03419681 \\ https://hal.science/hal-03419681}

Submitted on 8 Nov 2021

HAL is a multi-disciplinary open access archive for the deposit and dissemination of scientific research documents, whether they are published or not. The documents may come from teaching and research institutions in France or abroad, or from public or private research centers.
L'archive ouverte pluridisciplinaire HAL, est destinée au dépôt et à la diffusion de documents scientifiques de niveau recherche, publiés ou non, émanant des établissements d'enseignement et de recherche français ou étrangers, des laboratoires publics ou privés. 


\title{
Selective Separation of Cobalt and Nickel using a Stable Supported Ionic Liquid Membrane
}

\author{
Guillaume Zante, Maria Boltoeva, Abderrazak Masmoudi, Rémi Barillon, \\ Dominique Trébouet
}

\section{To cite this version:}

Guillaume Zante, Maria Boltoeva, Abderrazak Masmoudi, Rémi Barillon, Dominique Trébouet. Selective Separation of Cobalt and Nickel using a Stable Supported Ionic Liquid Membrane. Separation and Purification Technology, Elsevier, 2020, 252, pp.117477. 10.1016/j.seppur.2020.117477 . hal03419681

\section{HAL Id: hal-03419681 \\ https://hal.archives-ouvertes.fr/hal-03419681}

Submitted on 8 Nov 2021

HAL is a multi-disciplinary open access archive for the deposit and dissemination of scientific research documents, whether they are published or not. The documents may come from teaching and research institutions in France or abroad, or from public or private research centers.
L'archive ouverte pluridisciplinaire HAL, est destinée au dépôt et à la diffusion de documents scientifiques de niveau recherche, publiés ou non, émanant des établissements d'enseignement et de recherche français ou étrangers, des laboratoires publics ou privés. 


\title{
Selective Separation of Cobalt and Nickel using a Stable Supported Ionic Liquid Membrane
}

\author{
Guillaume Zante ${ }^{a, b, *}$, Maria Boltoevaa , Abderrazak Masmoudia, Rémi Barillon ${ }^{a}$, Dominique \\ Trébouet $^{a}$ \\ a Université de Strasbourg, CNRS, IPHC UMR 7178, F-67000 Strasbourg, France \\ ${ }^{\mathrm{b}}$ ADEME, 20 Avenue du Grésillé, 49004 Angers Cédex 01, France \\ *Corresponding author \\ E-mail address: guillaume.zante@etu.unistra.fr
}

\begin{abstract}
The selective separation of cobalt from nickel is of major importance for the recovery of cobalt from primary or secondary sources, as well as for analytical purposes. In this paper, the extraction of cobalt from the mixtures was examined using a supported liquid membrane employing the undiluted hydrophobic ionic liquid, namely tri(hexyl)tetradecyl phosphonium chloride $\left(\left[\mathrm{P}_{66614}\right][\mathrm{Cl}]\right)$, as a carrier and polyvinylidene difluoride (PVDF) as a membrane material.

In the preliminary study, the efficiency of this supported ionic liquid membrane (SILM) for the cobalt extraction was evaluated by conventional static mode sorption experiments. Up to $86 \%$ of cobalt can be recovered under optimal conditions (by contacting SILM with 9.8 $\mathrm{cm}^{2}$ in $5 \mathrm{~mL}$ of aqueous phase for 1 hour at $100 \mathrm{rpm}$, with $9 \mathrm{~mol} . \mathrm{L}^{-1} \mathrm{HCl}$ in the aqueous phase).

Next, metal ion transport through a flat sheet SILM was investigated with pure water as a receiving phase. Permeation coefficients values of $2.2 \times 10^{-6} \mathrm{~m} \cdot \mathrm{s}^{-1}$ and $8.0 \times 10^{-6} \mathrm{~m} \cdot \mathrm{s}^{-1}$ were obtained with a hydrophobic and a hydrophilic membrane, respectively. The SILM showed selectivity for cobalt over nickel with separation factors as high as 218 . Membrane stability was proven to be excellent, since the same SILM was used three times without losses of performances.
\end{abstract}

Keywords: Cobalt; Nickel; Selective separation; Supported ionic liquid membrane; Acid recovery.

\section{Introduction}

Cobalt is a widely used metal for numerous applications, from alloys to rechargeable lithiumion batteries (close to $50 \%$ of the world's cobalt supplied today) [1], [2], [3]. Cobalt demand is expected to rise strongly with the growth of the rechargeable battery market for electric vehicles ([3], [4]) that could result in a significant increase in the supply risk for this transition metal in the years to come [5].

To meet this growing demand, extraction and separation of cobalt from primary ([6]) and secondary sources ([7], [8]) has attracted much attention. The recycling of spent lithium-ion batteries and permanent magnets in view of cobalt recovery has been extensively studied recently ([9],[10],[11],[12],[13],[14],[15]). Separation and microextraction of divalent cobalt ion are also an important issue for analytical chemistry purposes ([16], [17], [18], [19]). 
In most of the reports, the hydrometallurgical road used implies to extract the target metal ion from aqueous solutions and to recover it with the highest purity as possible. The separation of cobalt from nickel is still a challenging task due to their proximity in the Periodic Table of the Elements and, subsequently, their similar aqueous chemical behavior.

Various techniques were reported to separate cobalt from nickel and other impurities such as iron, aluminum, and magnesium. Ion exchange resins ([20], [21], [22]), and solvent extraction ([23], [24], [25]) are among the most studied ones. However, ion exchange resins lack selectivity for cobalt and are more suitable for nickel extraction [20]. The extracting molecule bis(trimethylpentyl)phosphinic acid is particularly indicated for the extraction of cobalt from sulfuric acid media [24].

In hydrochloric acid media, several studies enlightened the possibility to form the lipophilic anionic complex of cobalt, $\mathrm{CoCl}_{4}{ }^{2-}$, which can then be extracted by amine type ligands diluted in hydrocarbon solvents ([26], [27], [28], [29]). Since divalent nickel does not form anionic complexes with chloride anions, high separation factors between these two metals can be obtained. However, solvent extraction implies to use large volumes of organic solvents that generates secondary streams of wastes.

Recently, Binnemans et al. used the undiluted commercial hydrophobic room-temperature ionic liquid (IL), namely tri(hexyl)tetradecyl phosphonium chloride for the cobalt-nickel separation [30], [31]. This IL allowed to obtain a highly selective extraction with $\mathrm{Co} / \mathrm{Ni}$ separation factor about 50000 . Even though this phosphonium-based IL could not be declared non-toxic, its toxicity is lower than ILs incorporating fluorinated anionic parts ([32], [33], [34]). Moreover, it possesses low aqueous solubility (20-80 ppm, [35]).

Using ionic liquids as diluents offers several advantages due to their unique physicochemical properties such as low flammability and negligible vapor pressure ([36], [37]). However, their application for the solvent extraction of metals is compromised since the volume of reagents needed is still very large. Another important issue is the high viscosity of the ILs, which increases the energy needed to mix the organic and aqueous phase.

On the other hand, significant viscosity of ILs is an advantage in the context of supported liquid membranes (SLMs). In this separation technique, the solvent phase composed of extractant molecules (also called the carrier) and diluent is embedded within the micropores of polymeric membrane material. Then, SLM prepared is placed between an aqueous feed and receiving phase, assuring the selective transport of the metals from one phase to another. Sustainable liquid membranes can be prepared by selecting an appropriate solvent phase embedded in the membrane, which could also help to provide a SLM with higher stability [38], [39]. The high viscosity of the ILs ensures higher capillary forces [40], which prevent them from being washed from the pores of the membrane. SLM based on highly viscous ILs were proven to improve their long term stability [41].

In this work, we developed a supported ionic liquid membrane (SILM) based on tri(hexyl)tetradecyl phosphonium chloride $\left(\left[\mathrm{P}_{66614}\right][\mathrm{Cl}]\right)$ for the extraction of cobalt from hydrochloric acid media and its separation from nickel. Preliminary, the effect of various parameters on cobalt extraction efficiency was studied. The SILM was used as a sorbent for cobalt ions. In the second part of the present study, we used the SILM in a continuous mode, 
where cobalt is selectively extracted and transported across the supported liquid membrane and then stripped to a second aqueous phase, without any stripping reagent [30].

The effect of membrane material has to be considered. For example, using a hydrophobic membrane is known to increase the thickness of the boundary layers at its interfaces [42]. Thus, the effect of membrane support hydrophilicity was investigated and was shown to have major importance on cobalt transport. Membrane stability was proven to be excellent, with the possibility to use the same SILM at least three times. Finally, we evidenced the transport of acids across the SILM, which could be used to recycle mineral acids using the SILM designed. The novelty of this work lies in the minimization of the volume of organic reagents needed to extract cobalt and separate it from nickel.

\section{Materials and methods}

\subsection{Reagents}

The room-temperature hydrophobic ionic liquid, tri(hexyl)tetradecyl phosphonium chloride (abbreviated as $\left[\mathrm{P}_{66614}\right][\mathrm{Cl}]$, purity $>97 \%, T_{\mathrm{m}}=-70^{\circ} \mathrm{C}$ ) was purchased from Solvionic (France). The relevant physicochemical properties are displayed in Table 1.

Table 1. Physicochemical properties of the $\left[\mathrm{P}_{66614}\right][\mathrm{Cl}] \mathrm{IL}$. Values for the dry IL at room temperature, if not specified

\begin{tabular}{lll}
\hline Property & Value & Reference \\
\hline Solubility in water & $20-80 \mathrm{ppm}$ & {$[43]$} \\
Viscosity & $2729 \mathrm{cP}$ & {$[44]$} \\
& $95 \mathrm{cP}$ (water -aturated, $\left.60^{\circ} \mathrm{C}\right)$ & \\
Surface tension & $33.6 \mathrm{mN} \cdot \mathrm{m}^{-1}$ & {$[45]$} \\
Water solubility in the IL & $0.818(\mathrm{~mole}$ fraction) & {$[46]$} \\
& $8.7 \mathrm{wt} . \%$ (water-saturated, 60 & {$[30]$} \\
Density & $0.88 \mathrm{~g} \cdot \mathrm{mL}^{-1}$ & \\
& $0.90 \mathrm{~g} \cdot \mathrm{mL}^{-1}$ (water-saturated, $\left.60^{\circ} \mathrm{C}\right)$ & {$[30]$} \\
\hline
\end{tabular}

Nickel(II) and cobalt(II) chloride salts $\left(\mathrm{NiCl}_{2} \bullet 6 \mathrm{H}_{2} \mathrm{O}\right.$ and $\mathrm{CoCl}_{2} \bullet 6 \mathrm{H}_{2} \mathrm{O}$, purity=98\%) were purchased from Prolabo (France). The presence of impurities was checked by ICP-OES and was found to be negligible. Deionized water $(18 \mathrm{M} \Omega . \mathrm{cm})$ was obtained with a Purelab Option $\mathrm{Q}$ apparatus. Hydrophobic and hydrophilic porous polyvinylidene fluoride films (PVDF, Merck or Sterlitech) were used as the liquid membrane support. This material was selected due to its resistance to harsh chemical conditions [47]. The characteristics of these films are summarized in Table 1 . All of the chemicals were used as received.

Table 2. Properties of the PVDF supports used in this study. 


\begin{tabular}{ccccc}
\hline Hydrophobic/hydrophilic & $\begin{array}{c}\text { Diameter } \\
(\mathbf{c m})\end{array}$ & $\begin{array}{c}\text { Thickness } \\
(\mu \mathrm{m})\end{array}$ & $\begin{array}{c}\text { Nominal pore } \\
\text { size }(\mu \mathrm{m}) / \\
\text { porosity }(\%)\end{array}$ & Supplier \\
\hline Hydrophobic & 2.5 & 150 & $0.45 / 85$ & $\begin{array}{c}\text { Merck- } \\
\text { Millipore }\end{array}$ \\
\hline Hydrophobic & 2.5 & 150 & $0.22 / 85$ & $\begin{array}{c}\text { Merck- } \\
\text { Millipore }\end{array}$ \\
\hline Hydrophobic & 2.5 & 50 & $0.1 /-$ & Sterlitech \\
\hline Hydrophobic & 2.5 & 50 & $0.02 /-$ & Sterlitech \\
\hline Hydrophobic & 5.5 & 125 & $0.45 / 75$ & Merck- \\
\hline Hydrophilic & 5.5 & 125 & $0.45 / 75$ & Millipore \\
\hline
\end{tabular}

\subsection{Preparation of the SILM}

The SILM was prepared at room temperature according to previously reported procedures ([48]), by immersing a virgin PVDF film in $5 \mathrm{~mL}$ of pure $\mathrm{IL}$ for at least one night. The $\left[\mathrm{P}_{66614}\right][\mathrm{Cl}]$ was saturated with water before use by shaking it with an equal volume of purified water for one night [30]. The excess of IL on the surface of the membrane was then left to drip for a few seconds before use. The penetration of the IL into the membrane was confirmed by weighing before and after the impregnation.

\subsection{Extraction experiments of cobalt under static conditions}

The aqueous feed phases were prepared by dissolving the metal chloride salts into deionized water. The exact mass of metal salt was weighed with a Sartorius BP 2215 balance (precision $\pm 0.01 \mathrm{mg}$ ), while the deionized water (resistivity $=18.2 \mathrm{M} \Omega . \mathrm{cm}$ ) was obtained with a Purelab Option $\mathrm{Q}$ apparatus. The $\mathrm{pH}$ was measured by a $\mathrm{pH}$ meter (Eutech Instruments, $\mathrm{pH} 2100 \mathrm{x}$ apparatus, precision \pm 0.01 ). The extraction equilibria were studied by the conventional (batch) method at room temperature. So, a sample of the freshly prepared SILM (surface area $\left.=9.8 \mathrm{~cm}^{2}\right)$ was immersed in a known volume (10 $\mathrm{mL}$ if not otherwise specified) of the aqueous feed solution and agitated at $100 \mathrm{rpm}$. The concentration of metal ions in the aqueous phase before $\left(C_{\text {before }}\right)$ and after extraction $\left(C_{\text {after }}\right)$ was determined by ICP-OES (Varian 720 ES apparatus). The extraction efficiency of the metal $(E, \%)$ is calculated with the following equation:

$\mathrm{E}=\frac{C_{\text {before }}-C_{\text {after }}}{C_{\text {before }}} \times 100$

The volume variation of the aqueous phase before and after extraction was checked by removing the aqueous phase after extraction with micropipettes and was found to be negligible (less than $30 \mu \mathrm{L}$ of variation). The cobalt content used is $15 \mu \mathrm{mol}$ dissolved in 10 $\mathrm{mL}$ of the aqueous phase, except for the variation of cobalt initial content (were cobalt initial 
content is varied in the range $5-60 \mu \mathrm{moL}$ ). The aqueous $\mathrm{HCl}$ concentration was fixed at 9 mol. $\mathrm{L}^{-1}$ except for the experiment of the variation of the $\mathrm{HCl}$ concentration (varied in the range from 0 to 9 mol. $\left.\mathrm{L}^{-1}\right)$. Hydrophobic PVDF membranes were used, except for the experiment in which hydrophilic and hydrophobic polymers are compared. The pore size of the membranes is $0.45 \mu \mathrm{m}$, except for the variation of the pore size of the membrane (where membranes having a pore size of $0.02,0.1,0.22$ and $0.45 \mu \mathrm{m}$ were used). The extraction time is 60 minutes (except for the contact time experiment were the contact time is varied in the range of 0-60 minutes).

The stripping from the liquid membrane phase was studied by immersing the cobalt-loaded membrane in deionized water $(20 \mathrm{~mL})$ for one hour at $100 \mathrm{rpm}$.

The stripping efficiency $(S, \%)$ is calculated with the following equation:

$\mathrm{S}=\frac{C_{\text {after stripping }}}{C_{\text {before }}-C_{\text {after }}} \times 100$

where $C_{\text {after stripping }}$ is the metal concentration in the aqueous solution used for the stripping from the loaded SILM. The operation is repeated several times with fresh deionized water until cobalt is completely removed from the liquid membrane. The complete removal is checked by a mass balance between the amount of cobalt extracted in the liquid membrane and the amount of cobalt recovered in the stripping solution. The extraction and stripping step are schematized in the following figure:
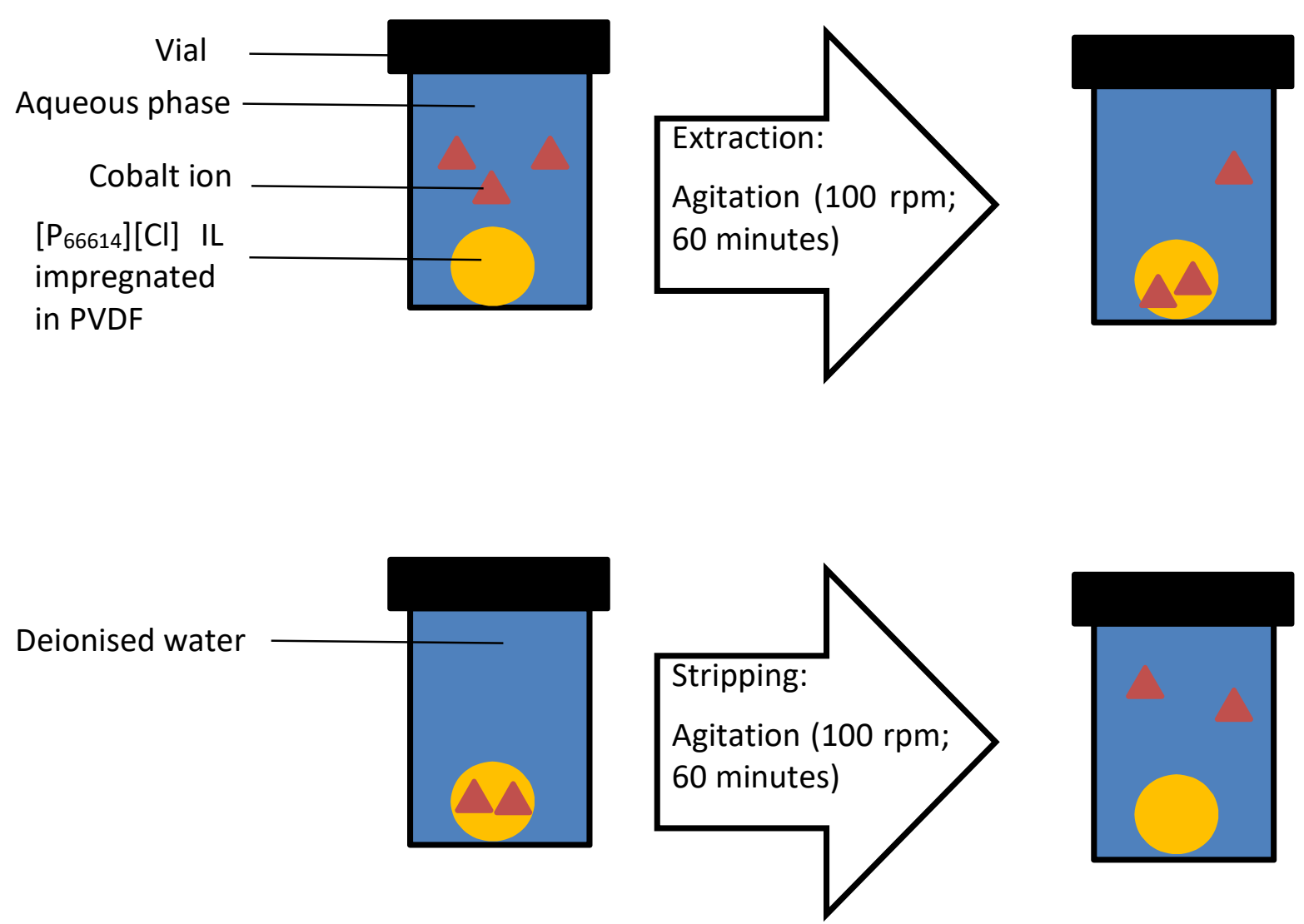

Figure 1. Scheme of the extraction (top) and stripping (down) procedures. 


\subsection{Membrane transport experiments}

A metal ion transport experiment was carried out using a glass experimental device (Verlabo) described in the previous study ([48]). The SILM (the effective area of $17.8 \mathrm{~cm}^{2}$ ) was placed between the two independent compartments for the feed and receiving aqueous phases ( $250 \mathrm{~mL}$ of each), which were agitated at $50 \mathrm{rpm}$ with glass agitators placed in each compartment, during 25 hours. Small aliquots from both aqueous solutions were withdrawn from the two aqueous phases at regular time intervals and the metal concentrations were determined by ICP-OES. The amount of cobalt recovered in the receiving phase at the time $($ ( $\mathrm{t}$ ") is calculated as follows:

Coreceiving phase $=\frac{[\mathrm{Co}]_{\text {receiving }, t}}{[\mathrm{Co}]_{\text {feed }, 0}}$

Where $[\mathrm{Co}]_{\text {feed,0 }}$ is the initial cobalt concentration at the start of the experiment, while $[\mathrm{Co}]_{\text {receiving, }}$ is the cobalt concentration in the receiving phase at time " $\mathrm{t}$ ".

The plot of the variation of the cobalt concentration in the feed phase against time allow us to calculate the permeation ratio $\left(P, \mathrm{~m}_{\mathrm{s}} \mathrm{s}^{-1}\right)[49]$.

$\ln \frac{[\mathrm{Co}]_{\text {feed }, t}}{[\mathrm{Co}]_{\text {feed }, 0}}=-\frac{A}{V} \times P \times t$

where $A$ is the membrane effective area and $V$ the volume of the aqueous phase. The initial flux $\left(\mathrm{J}_{0}, \mathrm{~mol} \cdot \mathrm{m}^{-2} \cdot \mathrm{s}^{-1}\right)$ is calculated according to the following equation [49]:

$J_{0}=P \times[C o]_{\text {feed }, 0}$

The separation factor $(S F)$ is calculated between cobalt and nickel is calculated as follows [50]:

$\mathrm{SF}=\frac{J_{0}(\mathrm{Co})}{J_{0}(\mathrm{Ni})}$

All of these experiments were repeated at least three times at ambient temperature $\left(25 \pm 2^{\circ} \mathrm{C}\right)$. Each experiment is run for 25 hours.

\section{Results and discussion}

3.1. Cobalt(II) extraction studies with SILM by static mode

\subsubsection{Impregnation of the membranes}

First, we studied the impregnation of various PVDF membranes with $\left[\mathrm{P}_{66614}\right][\mathrm{Cl}] \mathrm{IL}$. The results are displayed in Table 3.

Table 3. Mass of IL impregnated in the PVDF membranes.

\begin{tabular}{cccc}
\hline Membrane & Pore size $(\mu \mathrm{m})$ & Diameter $(\mathrm{cm})$ & $\begin{array}{c}\text { Mass of IL } \\
\text { immobilized }(\mathrm{mg})\end{array}$ \\
\hline Hydrophobic PVDF & 0.02 & 2.5 & $57.0 \pm 4.5$ \\
Hydrophobic PVDF & 0.1 & 2.5 & $51.5 \pm 2.9$
\end{tabular}


The mass of IL found in the membranes is obviously higher when the diameter of the membranes is higher $(5.5 \mathrm{~cm}$ against $2.5 \mathrm{~cm})$. The mass found is also close to whatever the hydrophilic or hydrophobic character of the polymer. For membranes of identical diameter $(2.5 \mathrm{~cm})$, the mass of IL is similar within the uncertainties, whatever the pore size of the membrane. This observation is different from what was previously reported for other ILs [48]. However, in this case, the IL is much more viscous and an external layer of IL will be deposited at the surface of the membrane. This external layer was evidenced with SEM images for various ILs ([51]) and is thicker with more viscous ILs.

\subsubsection{Effect of the contact time}

We investigated the effect of the contact time between a sample of SLIM prepared using hydrophobic PVDF (pore size $=0.45 \mu \mathrm{m}$ ) and tri(hexyl)tetradecyl phosphonium chloride $\left(\left[\mathrm{P}_{66614}\right][\mathrm{Cl}]\right)$ and the cobalt solution in the hydrochloric acid. The kinetics results of cobalt removal from the aqueous solution are shown in Figure 2.

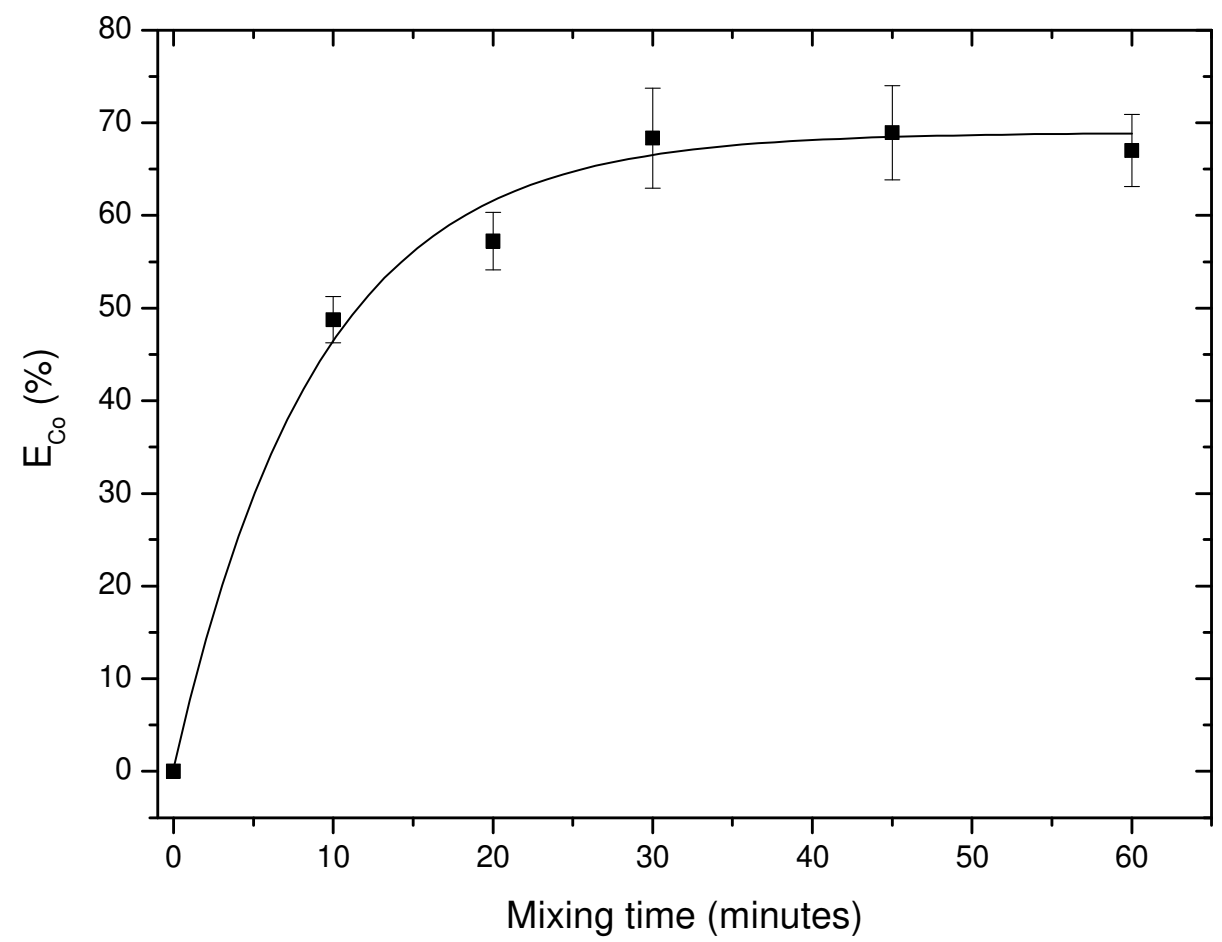

Figure 2. $E_{\mathrm{Co}}$ depending on the contact time between $\left[\mathrm{P}_{66614}\right][\mathrm{Cl}]$ based SILM and aqueous cobalt solution in $\mathrm{HCl}$ in the membrane extraction. Aqueous phase: $\mathrm{CoCl}_{2}\left(1.5 \mathrm{mmol}\right.$. $\left.\mathrm{L}^{-1}\right)$ in $\mathrm{HCl}\left(9 \mathrm{~mol}^{-\mathrm{L}^{-1}}\right)$. Membrane: hydrophobic PVDF (pore size $=0.45 \mu \mathrm{m}$ ). Membrane area $=9.8 \mathrm{~cm}^{2}$, volume of aqueous solution $=10 \mathrm{~mL}$

As can be seen, the prepared SILM is able to extract cobalt. The amount of cobalt extracted from $\mathrm{HCl}$ solution in the SILM is increasing with an increase of the contact time until it 
reaches a plateau for contact times higher than 30 minutes under the experimental conditions used. Cobalt extraction increases from $49 \%$ with a contact time of 10 minutes to $67 \%$ with a contact time of 60 minutes. The kinetics of this membrane extraction process is close to the time needed to extract cobalt with $\left[\mathrm{P}_{66614}\right][\mathrm{Cl}]$ using as extracting solvent (i.e. in liquid-liquid extraction), which is the time necessary to reach equilibrium [30]. A contact time of 1 hour is retained for further experiments to ensure that the extraction equilibrium is reached whatever the chemical conditions prevailing in the aqueous phase.

\subsubsection{Effect of aqueous $\mathrm{HCl}$ concentration}

The most important experimental parameter for the extraction of cobalt under its chlorocobalt complex is the concentration of chloride anion in the aqueous phase. The effect of the initial $\mathrm{HCl}$ concentration in the aqueous phase on the cobalt extractability with a sample of SILM based on $\left[\mathrm{P}_{66614}\right][\mathrm{Cl}]$ by the membrane extraction is evidenced in Figure 3.

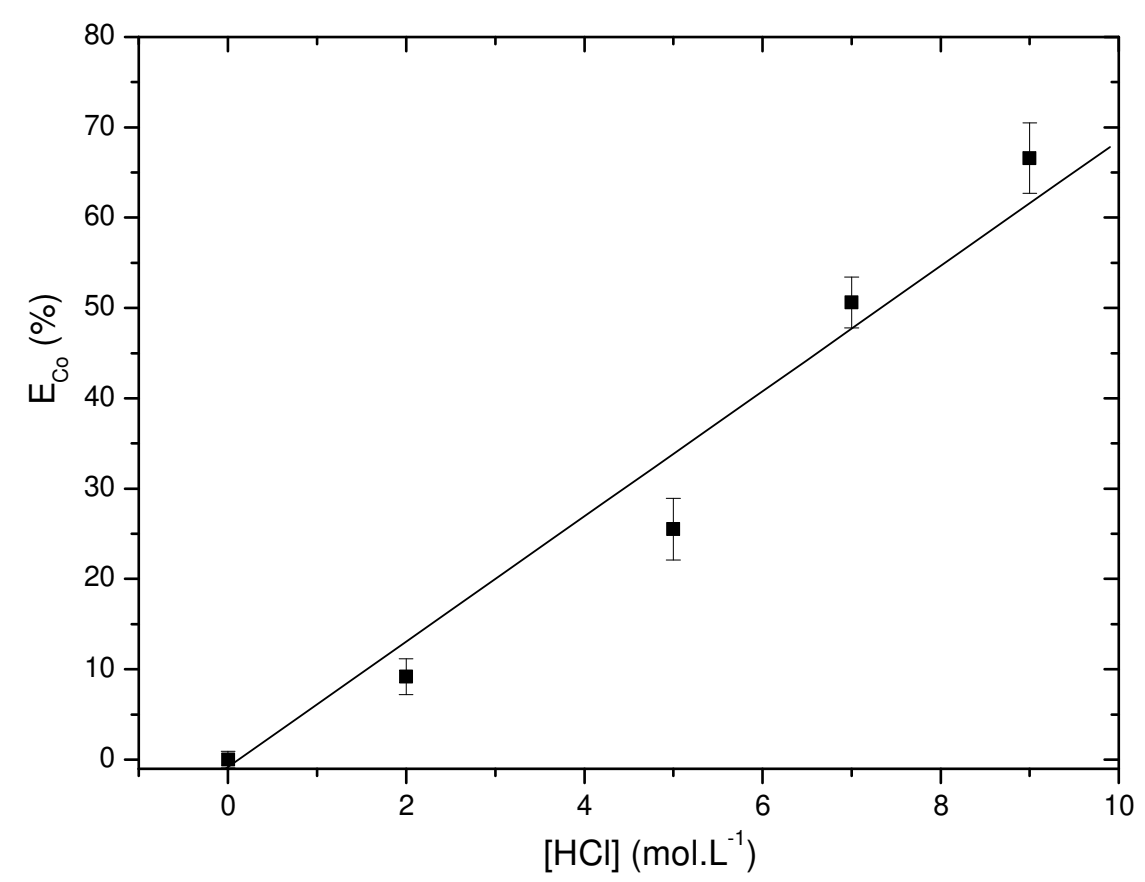

Figure 3. $E_{\mathrm{Co}}$ depending on the initial $\mathrm{HCl}$ concentration in the aqueous phase. Aqueous phase: $\mathrm{CoCl}_{2}$ $\left(1.5 \mathrm{mmol} . \mathrm{L}^{-1}\right)$ in $\mathrm{HCl}$ (variable). Membrane: hydrophobic PVDF (pore size $=0.45 \mu \mathrm{m}$ ). Membrane area $=9.8 \mathrm{~cm}^{2}$, volume of aqueous solution $=10 \mathrm{~mL}$. The contact time is $1 \mathrm{~h}$

The amount of cobalt extracted from the aqueous $\mathrm{HCl}$ solution is linearly increasing with the initial concentration of $\mathrm{HCl}$. Negligible extraction of cobalt is evidenced at $[\mathrm{HCl}]=0 \mathrm{M}$ in the aqueous phase. The extraction of cobalt increases and can reach values about $70 \%$ with 9 mol. $\mathrm{L}^{-1}$ of $\mathrm{HCl}$ in the aqueous phase. This rate is explained by the high amount of chloride anion in the aqueous phase needed to form the anionic complex $\mathrm{CoCl}_{4}{ }^{2-}$ and to allow its extraction by the phosphonium-based ionic liquid [52], [53]. Cobalt is extracted at the liquid membrane interface according to the following equation [30]:

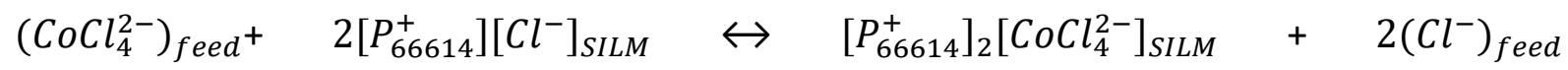
(7) 
where the subscripts "SILM" and "feed" refer to the SILM and aqueous feed phase, respectively. The aqueous initial concentration of $\mathrm{HCl}$ was fixed at $9 \mathrm{~mol}^{-\mathrm{L}^{-1}}$ for further experiments.

\subsubsection{Effect of the pore size of the membrane}

Next, the effect of the membrane pore size was investigated (Figure 4).

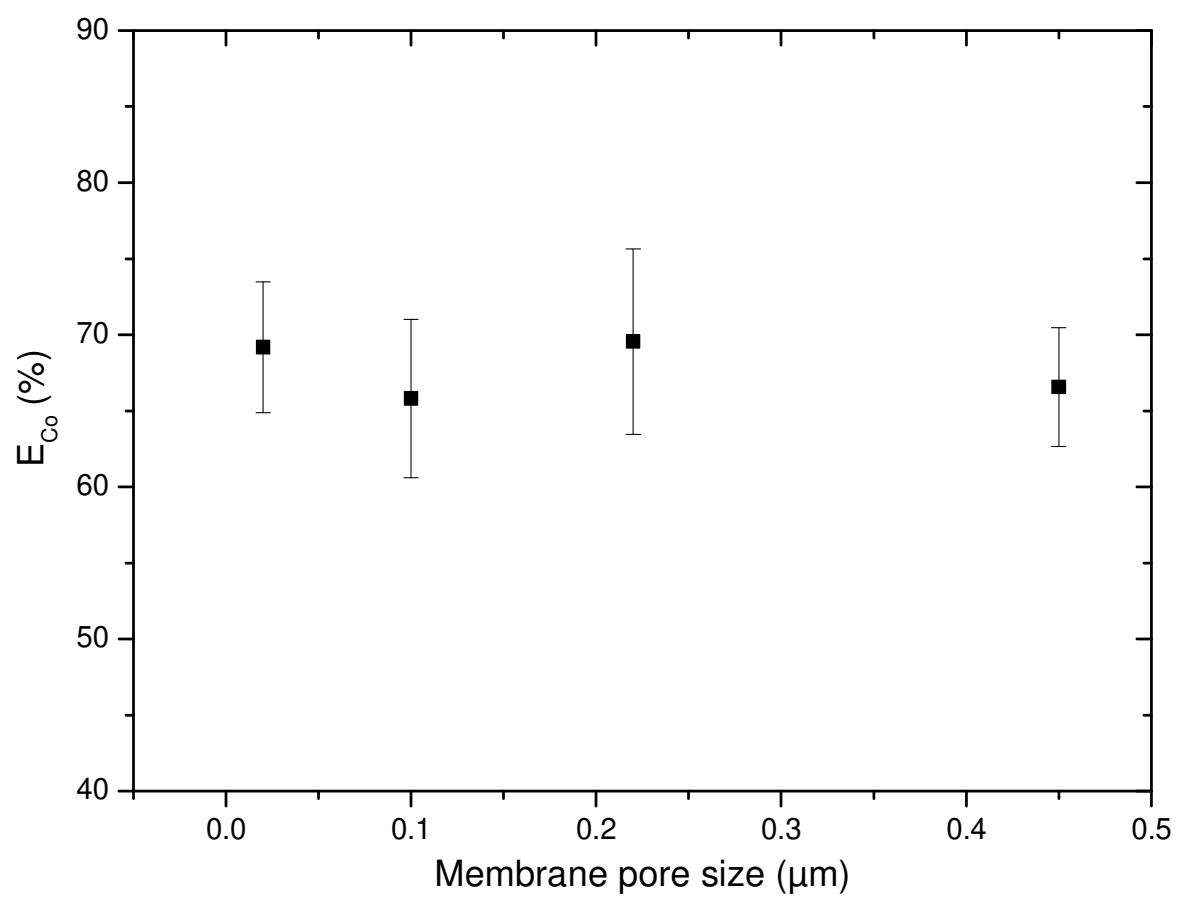

Figure 4. $E_{\mathrm{Co}}$ depending on the pore size of the polymeric membrane support. Aqueous phase: $\mathrm{CoCl}_{2}$ $\left(1.5 \mathrm{mmol} . \mathrm{L}^{-1}\right)$ in $\mathrm{HCl}\left(9 \mathrm{~mol} . \mathrm{L}^{-1}\right)$. Membrane: hydrophobic PVDF. Membrane area $=9.8 \mathrm{~cm}^{2}$, volume of aqueous solution $=10 \mathrm{~mL}$. The contact time is $1 \mathrm{~h}$

No significant differences in the cobalt extraction efficiency can be seen with the change in the support's pore size. Whatever the nominal pore size, the extractibility of cobalt from aqueous solution was in the range of $65-70 \%$. With this liquid membrane, the $\left[\mathrm{P}_{66614}\right][\mathrm{Cl}]$ ionic liquid is responsible for the extraction of the metal ion (no extraction occurs neither with the virgin hydrophobic polymer nor with the virgin hydrophilic polymer). It seems that cobalt is extracted at the interface between the SILM and the aqueous phase by the IL located at the interface. The IL being highly viscous, there is always an external layer of IL left on the membrane surface, whatever the impregnation method used [54]. Thus, the amount of IL available at the membrane interface is probably similar whatever the pore size of the membrane support, which could explain the similar extraction rates obtained.

\subsubsection{Effect of initial cobalt content}

A membrane pore size of $0.45 \mu \mathrm{m}$ was retained to study the effect of the cobalt content. To do so, the volume of the aqueous phase was varied in the range from 5 to $60 \mathrm{~mL}$ with the same cobalt concentration ( $\left.1.5 \mathrm{mmol} . \mathrm{L}^{-1}\right)$ and a constant membrane area (Figure 5). 


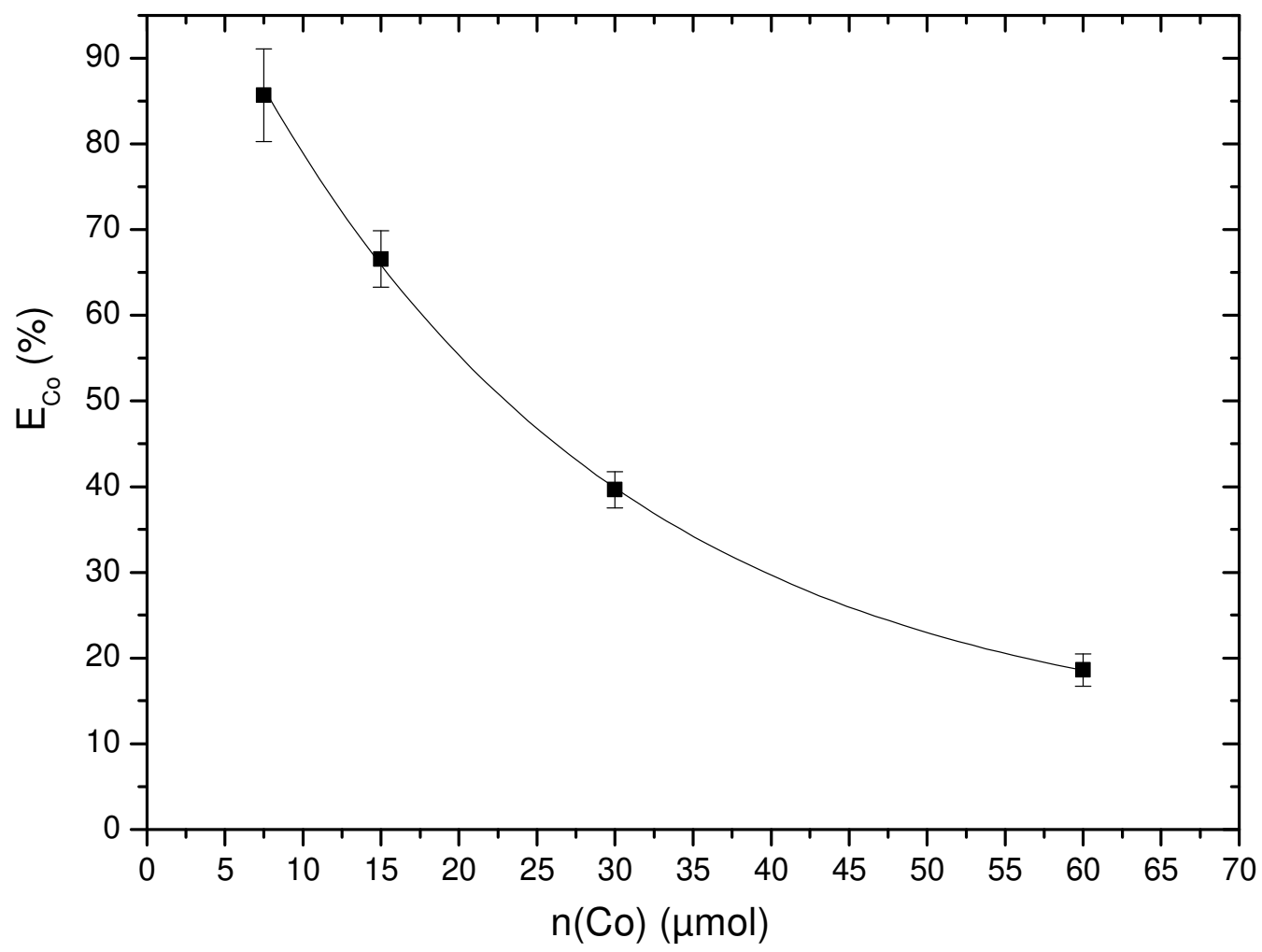

Figure 5. $E_{\mathrm{Co}}$ depending on the amount of cobalt ( $\left.\mu \mathrm{mol}\right)$ in the aqueous phase. Aqueous phase: $\mathrm{CoCl}_{2}$ (variable) in $\mathrm{HCl}\left(9 \mathrm{~mol}^{-1} \mathrm{~L}^{-1}\right.$. Membrane: hydrophobic PVDF (pore size $\left.=0.45 \mu \mathrm{m}\right)$. The membrane area is $9.8 \mathrm{~cm}^{2}$. The contact time is $1 \mathrm{~h}$

The cobalt extraction efficiency is highly dependent on the volume of the aqueous phase placed in contact with the SILM sample. With a low volume of the aqueous phase $(5 \mathrm{~mL})$, cobalt extraction efficiency can reach values up to $86 \%$. However, extraction efficiency decreases from $86 \%$ to $19 \%$ when the volume of the aqueous phase is increased from $5 \mathrm{~mL}$ to $40 \mathrm{~mL}$. The amount of IL in the SILM being low (around $50 \mathrm{mg}$ ), it is probably saturated with cobalt complexes, making it unable to accumulate more cobalt. The appearance of the membrane after extraction is shown in Figure 6.

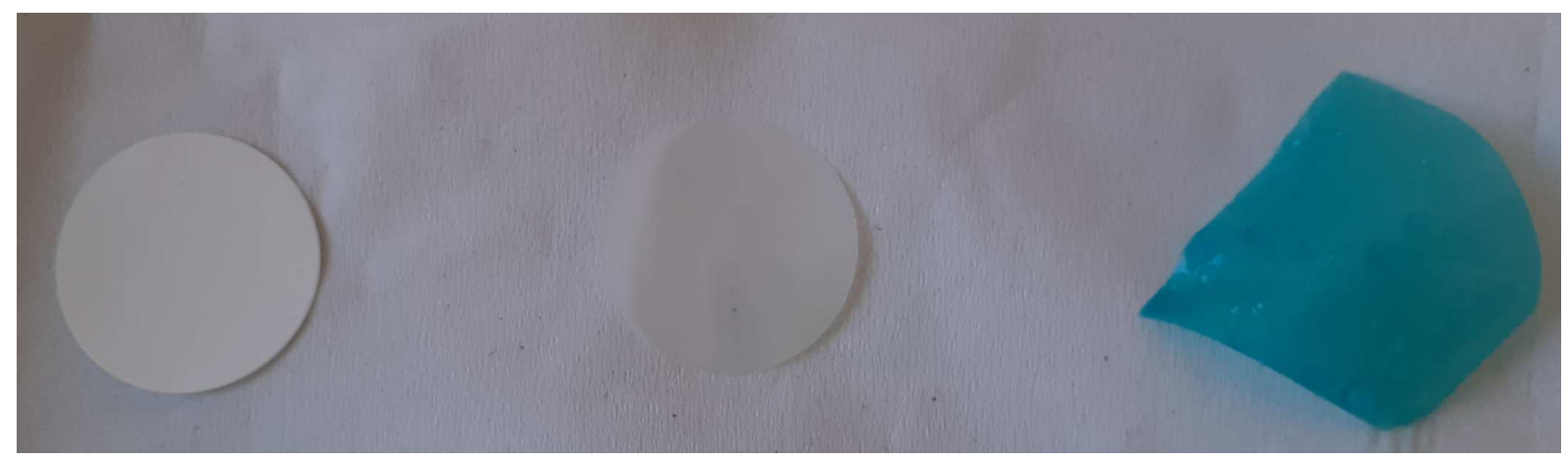

Figure 6. Picture of a porous membrane film before impregnation (left), after impregnation (middle), and of a piece of the SILM after extraction of cobalt from hydrochloric acid media (right).

The membrane turns from white to translucid after its impregnation with the $\mathrm{IL}$, which indicates that membrane pores and surface are filled with the IL. After the extraction step, 
the membrane color turns to blue, probing the extraction of cobalt chloride complex from the aqueous phase to the SILM by the $\left[\mathrm{P}_{66614}\right][\mathrm{Cl}] \mathrm{IL}$.

\subsubsection{Selectivity, stripping and SILM re-usability studies}

Recently, the selectivity of the $\left[\mathrm{P}_{66614}\right][\mathrm{Cl}] \mathrm{IL}$ for cobalt(II) over nickel(II) was proven to be unprecedently high [30] using solvent extraction. In the present study, the selectivity for cobalt and nickel was evaluated with the SILM incorporating the $\left[\mathrm{P}_{66614}\right][\mathrm{Cl}] \mathrm{IL}$ (Figure 7). As a matter of comparison, results are shown with a hydrophobic as well as a hydrophilic polymer, in the same conditions.

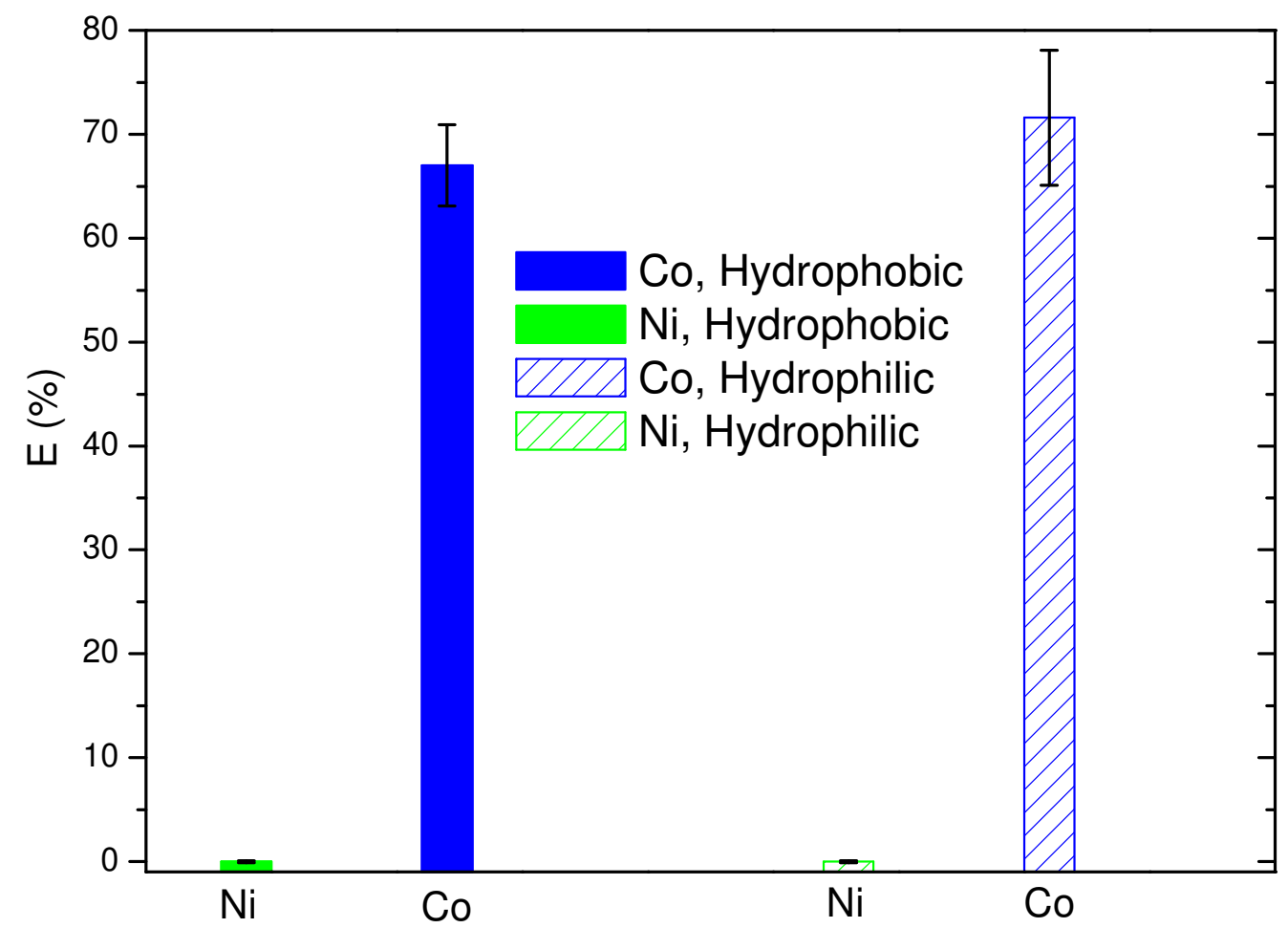

Figure 7. $E_{\mathrm{Co}}$ and $E_{\mathrm{Ni}}$ with an aqueous phase made of $\mathrm{CoCl}_{2}$ and $\mathrm{NiCl}_{2}\left(41.5 \mathrm{mmol} . \mathrm{L}^{-1}\right.$ of each) in $\mathrm{HCl}$ (9 mol. $\mathrm{L}^{-1}$ ). Membrane: hydrophobic or hydrophobic PVDF (pore size $=0.45 \mu \mathrm{m}$ ). Membrane area $=9.8$ $\mathrm{cm}^{2}$, volume of aqueous solution $=10 \mathrm{~mL}$. The contact time is $1 \mathrm{~h}$

Starting with an equimolar mixture of cobalt and nickel chlorides $\left(1.54 \mathrm{mmol}^{-\mathrm{L}^{-1}}\right)$, it can be seen that around $70 \%$ of the initial cobalt is extracted to the membrane phase, while the amount of nickel removed from the aqueous is indiscernible. The selectivity of the SILM is excellent since the phosphonium-based IL is only able to extract the anionic metallic species, while divalent nickel doesn't form anionic complexes in chloride media [55]. Fig. 7 shows that the selectivity is similar whatever the membrane used since no extraction of nickel occurs with neither with a hydrophilic nor with a hydrophobic polymer. It can also be seen that no significant differences in the extraction efficiency of cobalt were observed since $E_{\text {co }}$ values are close whatever a hydrophilic or hydrophobic polymer is used. To remove cobalt from the membrane phase and to potentially re-use the SILM, the stripping and re-usability studies were performed (Figure 8 and Figure 10). 


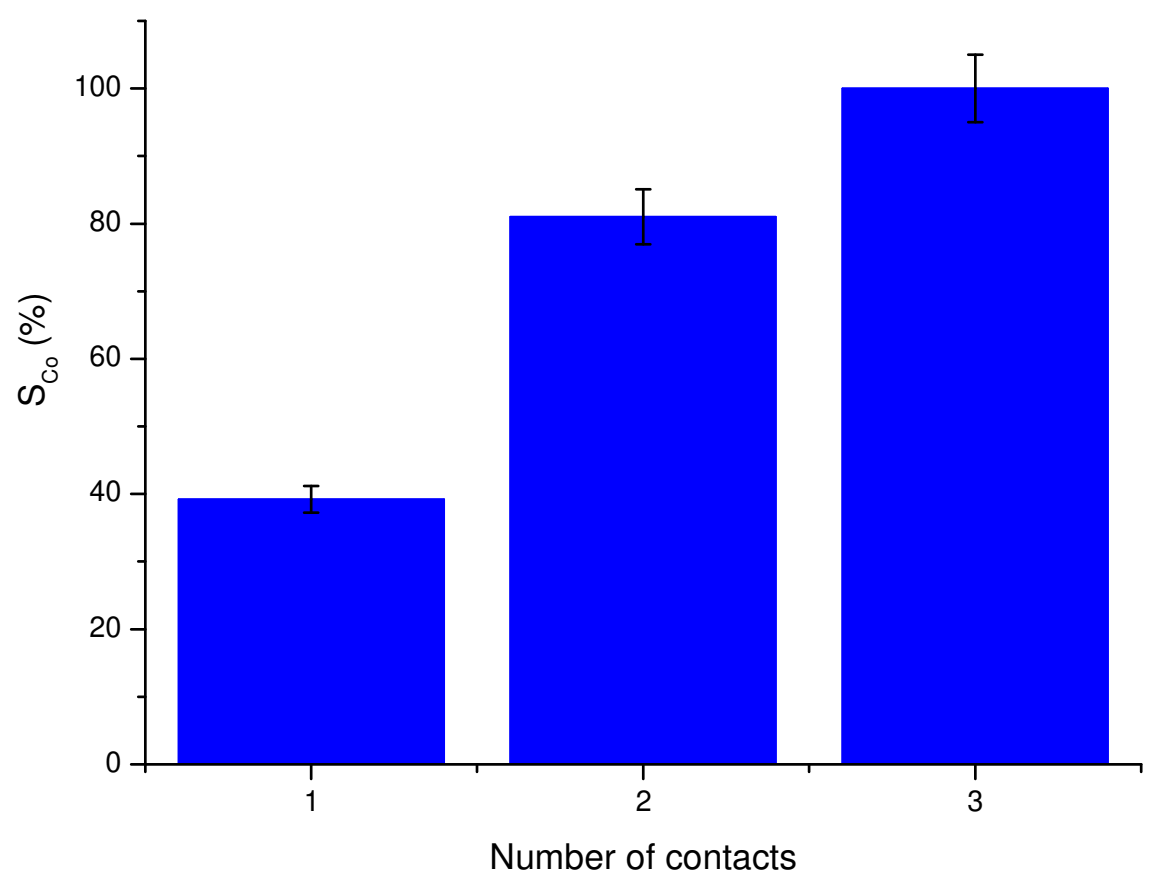

Figure 8. Amount of Co stripped from the membrane after extraction $\left(1.5 \mathrm{mmol} . \mathrm{L}^{-1}\right.$ in $\mathrm{HCl} 9 \mathrm{~mol} . \mathrm{L}^{-1}$, $\mathrm{V}=10 \mathrm{~mL})$. Stripping solution: deionised water $(\mathrm{V}=20 \mathrm{~mL})$ Membrane: hydrophobic PVDF (pore size $=$ $0.45 \mu \mathrm{m})$. Membrane area $=9.8 \mathrm{~cm}^{2}$. The contact time is $1 \mathrm{~h}$

Cobalt can be stripped from the SILM using pure water, according to Eq. (8) [30].

$\left[\mathrm{P}_{66614}^{+}\right]_{2}\left[\mathrm{CoCl}_{4}^{2-}\right]_{\text {SILM }}+\left(\mathrm{H}_{2} \mathrm{O}\right)_{\text {SILM }} \leftrightarrow 2\left[\mathrm{P}_{66614}^{+}\right]\left[\mathrm{Cl}^{-}\right]_{\text {SILM }}+\left(\mathrm{CoCl}_{2}\right)_{\text {stripping }}+\left(\mathrm{H}_{2} \mathrm{O}\right)_{\text {SILM }}$

The subscript "stripping" refers to the aqueous stripping phase. However, a large volume of water is necessary. Three successive contacts with $20 \mathrm{~mL}$ of fresh water are necessary to remove completely the extracted cobalt from the membrane. The re-usability of the membrane was evaluated by using the same membrane over three cycles of extractionstripping (Figure 9). 


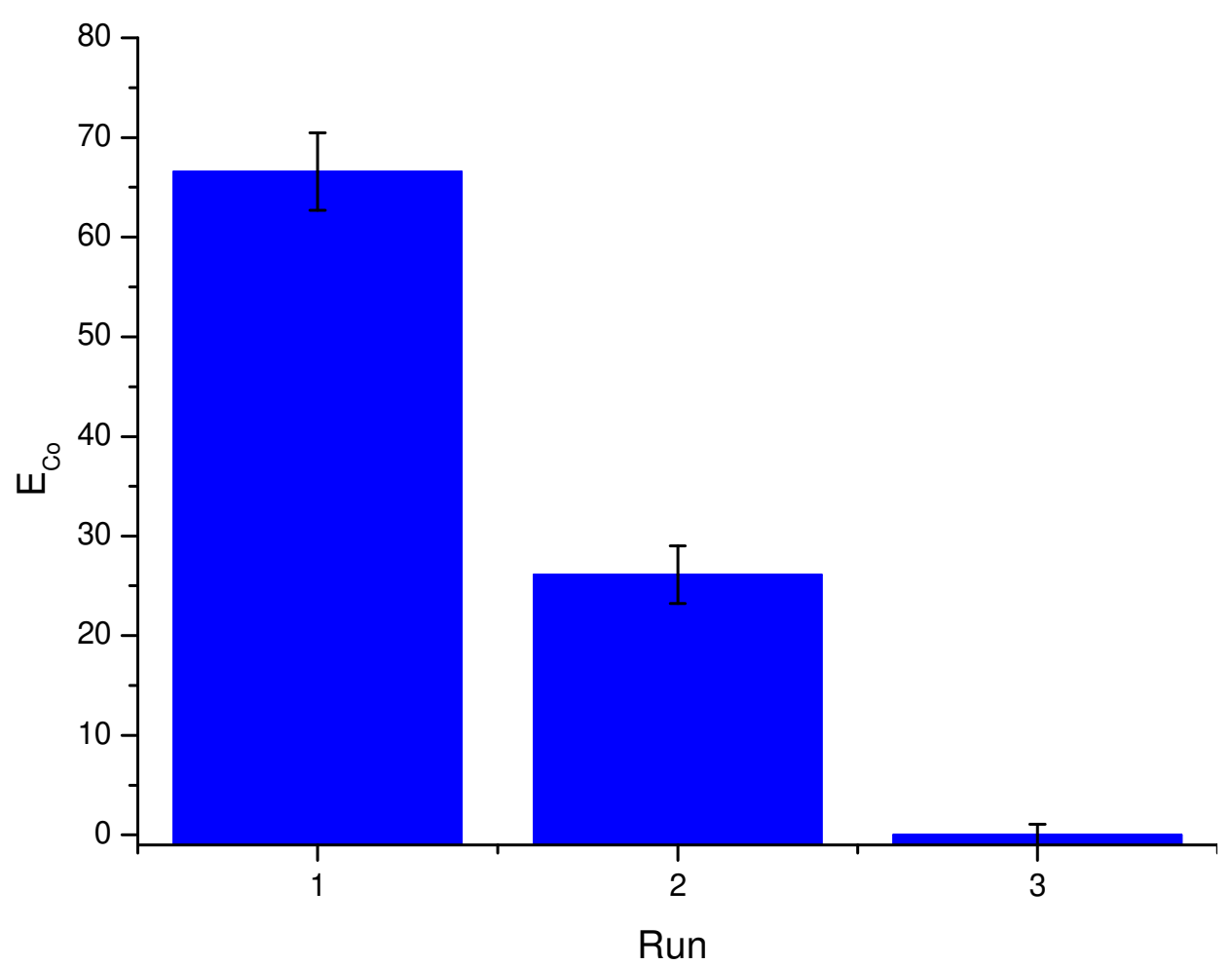

Figure 9. Amount of Co extracted over three consecutive cycles (60 minutes each) of extraction/stripping with the same SILM membrane. Aqueous phase: $\mathrm{CoCl}_{2}\left(1.5 \mathrm{mmol}\right.$. $\left.\mathrm{L}^{-1}\right)$ in $\mathrm{HCl}(9$ mol. $L^{-1}$ ). Membrane: hydrophobic PVDF (pore size $=0.45 \mu \mathrm{m}$ ). Membrane area $=9.8 \mathrm{~cm}^{2}$, volume of solution=10 $\mathrm{mL}$. Stripping is conducted with three successive contacts with deionized water $(\mathrm{V}=20 \mathrm{~mL}$ of fresh water at each contact).

While the extraction of cobalt is sufficiently high after the first extraction cycle (67\%), the extraction efficiency for cobalt is only about $26 \%$ on the second cycle. The complete stripping of the metal (checked by mass balance) is done before each new run. Negligible extraction was obtained in the third cycle of extraction. The membrane performances are degraded after several cycles of extraction. After each extraction-stripping step, a slight amount of IL is leached from the membrane surface because of aqueous solubility of IL. When the amount of IL in the SILM becomes too low, it affects the extraction efficiency.

\subsection{Metal extraction using SILM and effect of membrane hydrophobicity}

The SILM based on $\left[\mathrm{P}_{66614}\right][\mathrm{Cl}]$ ionic liquid can be used in a continuous mode with a membrane contactor, allowing to extract cobalt from a feed phase and to strip it in a receiving phase. Pure water was selected as a receiving phase since it allows the recovery of cobalt from the IL phase (Figure 8). The time evolution of cobalt ion concentrations in both aqueous phases is displayed in Figure 10. 


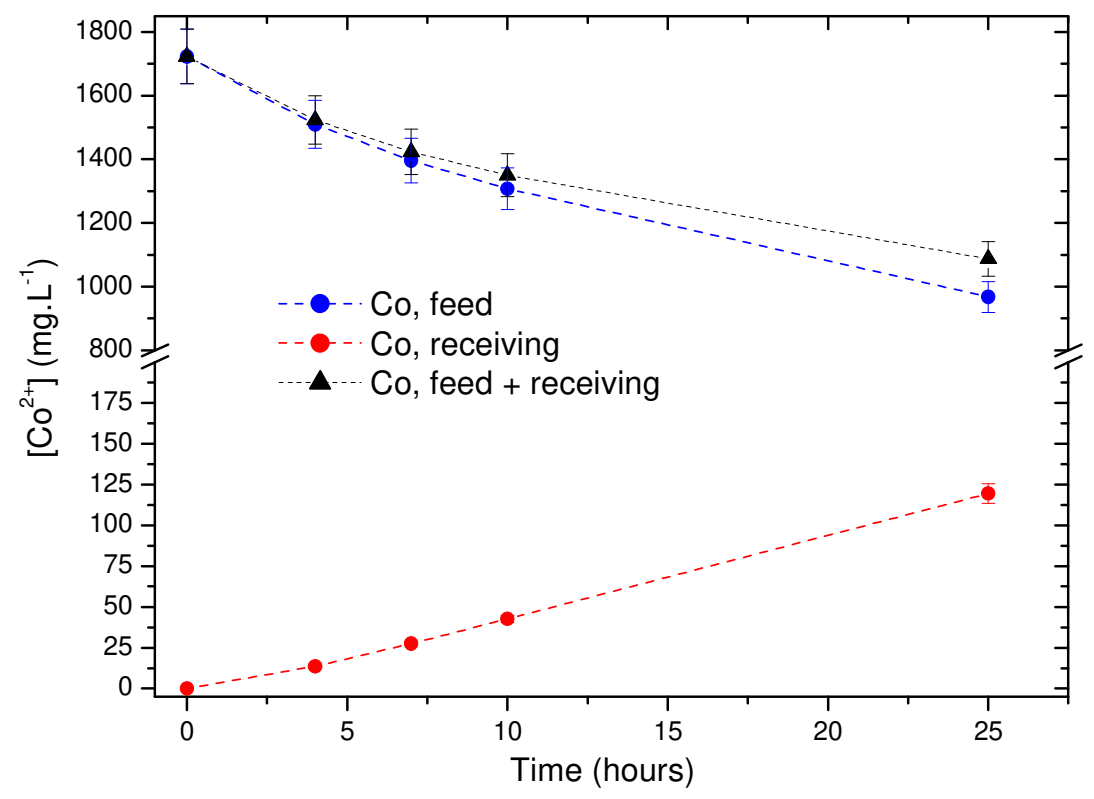

Figure 10. Time courses of cobalt ion concentration in the aqueous feed and receiving phases during IL-based SLM operation. Feed phase: $\mathrm{CoCl}_{2}(1.7 \mathrm{~g} . \mathrm{L}-1)$ in $\mathrm{HCl}(9$ mol.L-1 $)$. Receiving phase: deionized water. Membrane phase: $\left[\mathrm{P}_{66614}\right][\mathrm{Cl}]$ in hydrophobic PVDF. Pore size $=0.45 \mu \mathrm{m}$. Effective area $=17.8 \mathrm{~cm}^{2}$

It can be seen that cobalt concentration in the feed phase is gradually decreasing, indicating that cobalt is extracted at the feed/liquid membrane interface according to Eq. (7). [30]

Meanwhile, the cobalt content in the receiving phase is increasing. However, cobalt is not entirely stripped from the SILM phase, since the addition of cobalt concentration in the feed + receiving phase is not equal to the initial amount of cobalt introduced in the feed phase. The affinity of cobalt for the IL is too strong and a significant amount of cobalt accumulates in the membrane phase.

However, an interesting phenomenon was observed with the IL embedded in the hydrophobic polymer. As evidenced in Figure 11, the $\mathrm{pH}$ of the aqueous receiving phase is gradually decreasing, which proves that acid protons are transported through the SILM. 


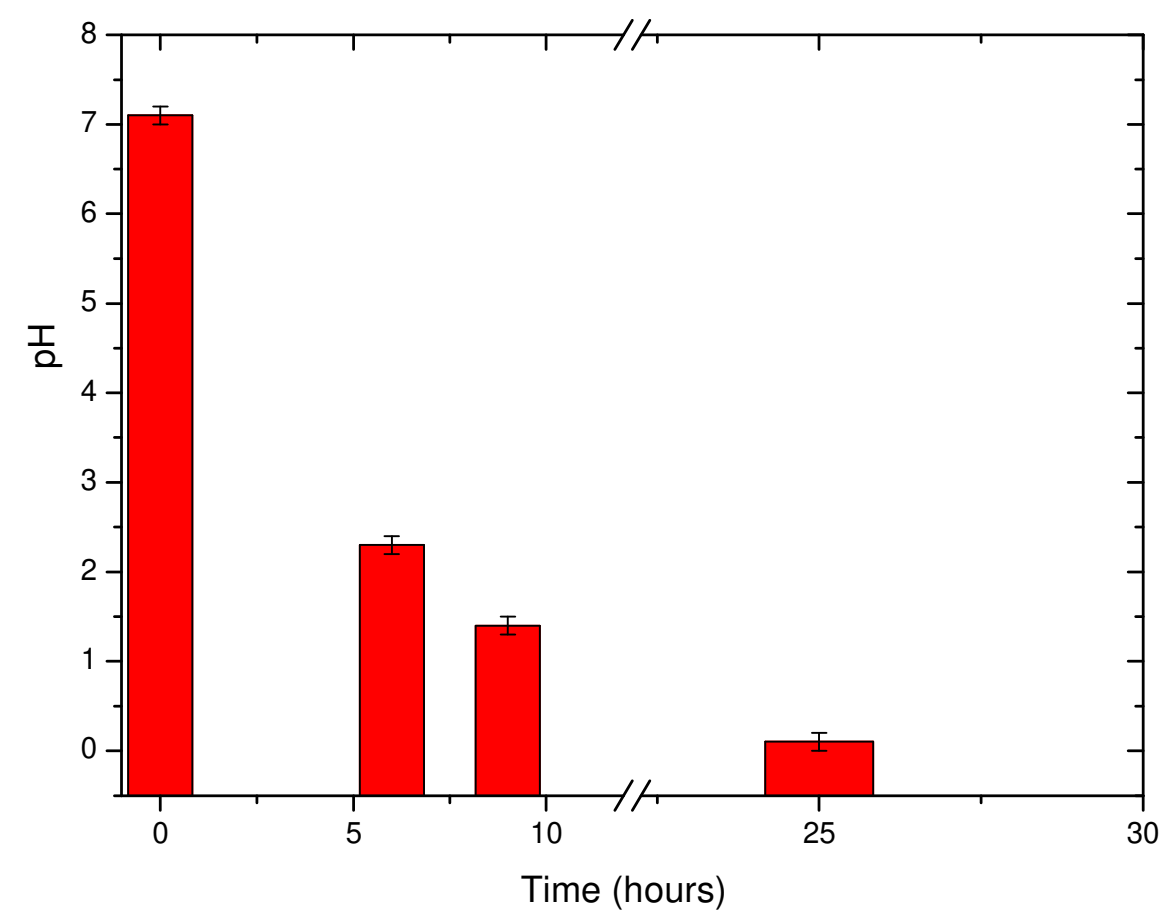

Figure 11. Time evolution of $\mathrm{pH}$ in the aqueous receiving phase. Feed phase: $\mathrm{CoCl}_{2}(1.7 \mathrm{~g} . \mathrm{L}-1)$ in $\mathrm{HCl}(9$ mol.L-1). Receiving phase: de-ionised water. Liquid membrane: $\left[\mathrm{P}_{66614}\right][\mathrm{Cl}]$ in hydrophobic PVDF.

It is well known that the ILs are hygroscopic and can incorporate in their structure a large amount of water and acid. Using SILMs based on these highly hygroscopic ILs, dynamic clusters, and water micro-environments can be formed inside the IL [56]. These microenvironments constitute a potential path to transport water-soluble compounds. In our case, it could constitute a way to recycle and purify the acid used in the feed phase. To further confirm this effect, we studied the evolution of the $\mathrm{pH}$ in the feed and receiving phases. The feed phase is made of hydrochloric acid, the receiving phase is made of deionised water. To confirm that the acid is not contaminated with metals in the receiving phase, we added nickel in the feed phase. The results are displayed in the following figure. 

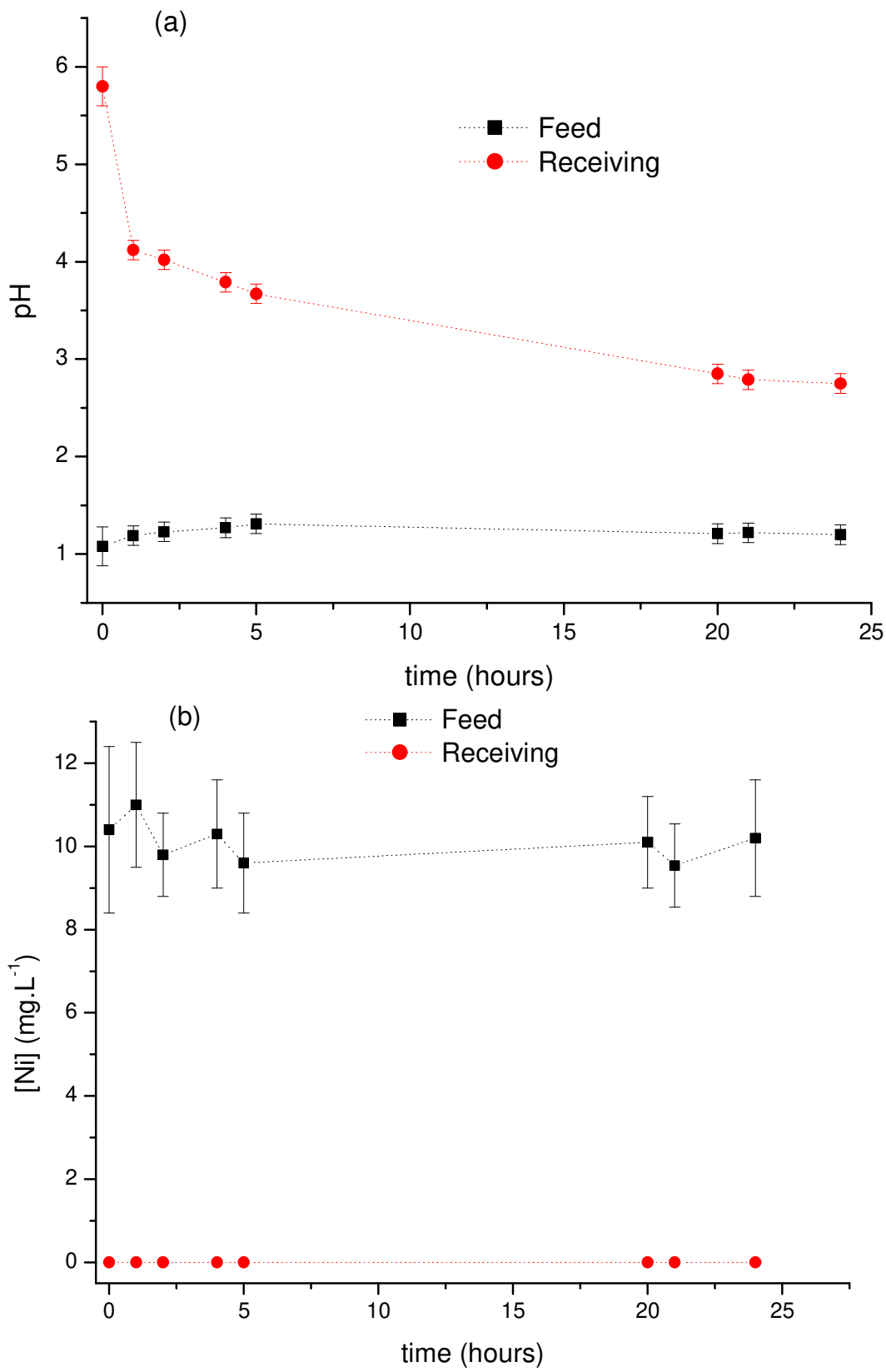

Figure 12. (a) Evolution of $\mathrm{pH}$ in the feed and receiving phases. (b) Evolution of nickel concentration in the feed and receiving phases. Feed phase: $\mathrm{NiCl}_{2}(10 \mathrm{mg}$.L-1) in $\mathrm{HCl}(0.1$ mol.L-1). Receiving phase: deionised water. Liquid membrane: $\left[\mathrm{P}_{66614}\right][\mathrm{Cl}]$ in hydrophobic PVDF.

As evidenced in Fig. 12 (a), the $\mathrm{pH}$ of the feed phase is decreasing over time, which could be related to the diffusion of protons from the feed to the receiving phase. Fig. 12 (b) shows that nickel ions remain in the feed phase since there is no extraction of nickel with the IL. The concentration of nickel found in the receiving phase is below the detection limit $\left(0.1 \mathrm{mg} \cdot \mathrm{L}^{-1}\right)$ during the experiment.

Since the positively charged compounds are not transported across the membrane and the anionic complexes are poorly stripped from the membrane, the acid could be recovered in the receiving phase and decontaminated from the metals. This SILM process could be an alternative to processes based on expensive electrodialysis and anion exchange membranes frequently reported for the purification and recovery of mineral acids ([57], [58], [59], [60], 
[61]). However, the recovery of acids is out of the scope of this study and it was not studied further.

While the extraction of cobalt ions (Eq. 73 ) is efficient with the hydrophobic polymer, its stripping is complex. To improve the stripping, water has to be available to wash the excess of chloride anion in the IL at the SILM/receiving phase interface according to Eq. (8).

This reaction is not favored with a hydrophobic polymer since it does not let penetrate water, and consequently limits the stripping of cobalt. By switching from hydrophobic PVDF to hydrophilic one, the stripping of cobalt is now complete, as evidenced in Fig. 13.

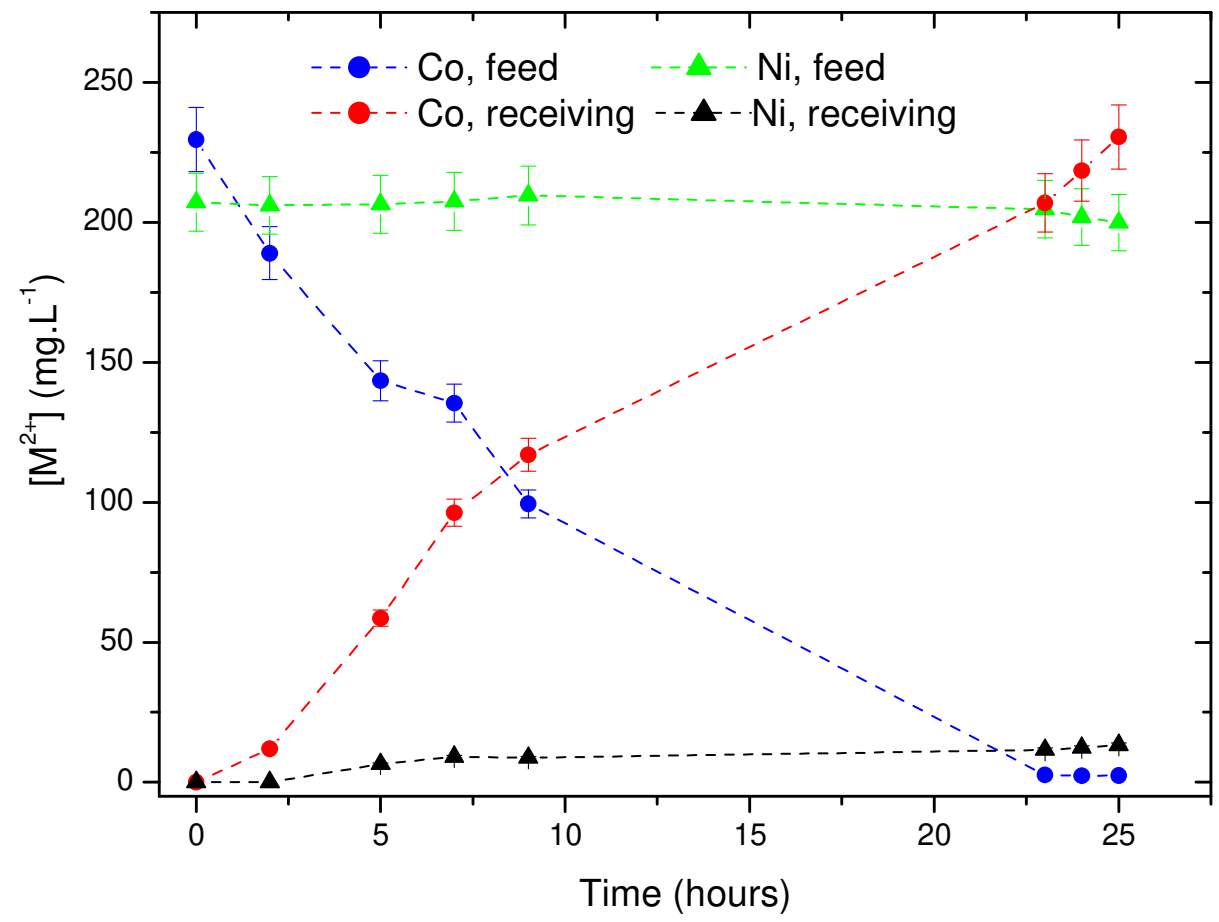

Figure 13. Time courses of cobalt and nickel ion concentration in the aqueous feed and receiving phases. Feed phase: $\mathrm{CoCl}_{2}$ (230 mg.L-1) and $\mathrm{NiCl}_{2}(210 \mathrm{mg}$.L-1) in $\mathrm{HCl}$ (9 mol.L-1). Receiving phase: deionised water. Liquid membrane: $\left[\mathrm{P}_{66614}\right][\mathrm{Cl}]$ in hydrophilic PVDF.

The initial aqueous feed solution contained a mixture of cobalt and nickel chlorides. The concentration of cobalt ions is gradually decreasing in the feed phase and gradually increasing in the receiving phase. After 25 hours of SILM operation, the totality of the initial cobalt placed in the feed solution was found in the receiving solution. It seems that cobalt is transported across the membrane in a solution diffusion-mechanism, characterized by stable complexes [62]. The IL-cobalt complexes $\left(\left[\mathrm{P}_{66614}^{+}\right]\left[\mathrm{CoCl}_{4}^{2-}\right]\right)$ migrates from the feed to the receiving phase, while the IL $\left(\left[P_{66614}^{+}\right]\left[\mathrm{Cl}^{-}\right]\right)$migrates through the membrane in the opposite direction. As can be seen in Fig. 13, nickel ion concentration in the feed phase remains almost constant throughout the experiment. However, a slight amount of nickel is recovered in the receiving phase after 25 hours $\left(11.5 \mathrm{mg} \cdot \mathrm{L}^{-1}\right.$, representing $5.6 \%$ of the initial nickel placed in the feed solution). Since nickel is not extracted by the IL, the transport of low concentrations of nickel could be related to the micro-environments of water inside the SILM. These micro-environments constitute non-selective paths in which water-soluble compounds such as nickel ions can be transported across the polymeric support. These micro-environments are presumably more pronounced with hydrophilic support. 
The comparison between hydrophobic and hydrophobic membrane for cobalt transport was made. The results are displayed in Table 4.

Table 4. Comparison of the results obtained with hydrophilic or hydrophobic membranes. Feed phase: $\mathrm{CoCl}_{2}$ (230 mg.L-1) and $\mathrm{NiCl}_{2}(210 \mathrm{mg} . \mathrm{L}-1)$ in $\mathrm{HCl}$ (9 mol.L-1). Receiving phase: de-ionised water. Liquid membrane: $\left[\mathrm{P}_{66614}\right][\mathrm{Cl}]$ in hydrophilic PVDF.

\begin{tabular}{cccc}
\hline Membrane & $\mathrm{P}\left(\mathrm{m} . \mathrm{s}^{-1}\right)$ & $\mathrm{J}_{0}\left(\mathrm{~mol} . \mathrm{m}^{-2} . \mathrm{s}^{-1}\right)$ & $\mathrm{SF} \mathrm{Co} / \mathrm{Ni}$ \\
\hline Hydrophobic PVDF & $2.2 \times 10^{-6} \pm 2.2 \times 10^{-7}$ & $5.0 \times 10^{-6} \pm 4.2 \times 10^{-7}$ & - \\
Hydrophilic PVDF & $8.0 \times 10^{-6} \pm 5.4 \times 10^{-7}$ & $1.4 \times 10^{-5} \pm 1.2 \times 10^{-6}$ & $218 \pm 8$ \\
\hline
\end{tabular}

The permeation ratio values obtained are $2.2 \times 10^{-6} \pm 2.2 \times 10^{-7} \mathrm{~m} \cdot \mathrm{s}^{-1}$ and $8.0 \times 10^{-6} \pm 5.4 \times 10^{-7} \mathrm{~m} \cdot \mathrm{s}^{-1}$ for the hydrophobic and the hydrophilic polymer, respectively. The metal ion flux value is $1.4 \times 10^{-5} \pm 1.2 \times 10^{-6} \mathrm{~mol} . \mathrm{m}^{-2} . \mathrm{s}^{-1}$ for the hydrophilic polymer while the value obtained for the hydrophobic polymer is $5.0 \times 10^{-6} \pm 4.2 \times 10^{-7} \mathrm{~mol} . \mathrm{m}^{-2} . \mathrm{s}^{-1}$. It can be concluded that both permeation (P) and initial metal ion flux $\left(\mathrm{J}_{0}\right)$ of cobalt is higher when using a hydrophilic polymer rather than a hydrophobic one. This effect could be related to the higher thickness of the boundary layers with hydrophobic membranes [42]. It should also be mentioned that the stripping of the metal is not complete when using hydrophobic membranes. The separation factor for Co over Ni reaches values up to 208 when using a hydrophilic polymer. As already mentioned, this separation is better with a hydrophobic membrane, since no transport of nickel is obtained, which makes impossible to calculate the separation factor.

The proposed mechanism of extraction is displayed in the following figure:

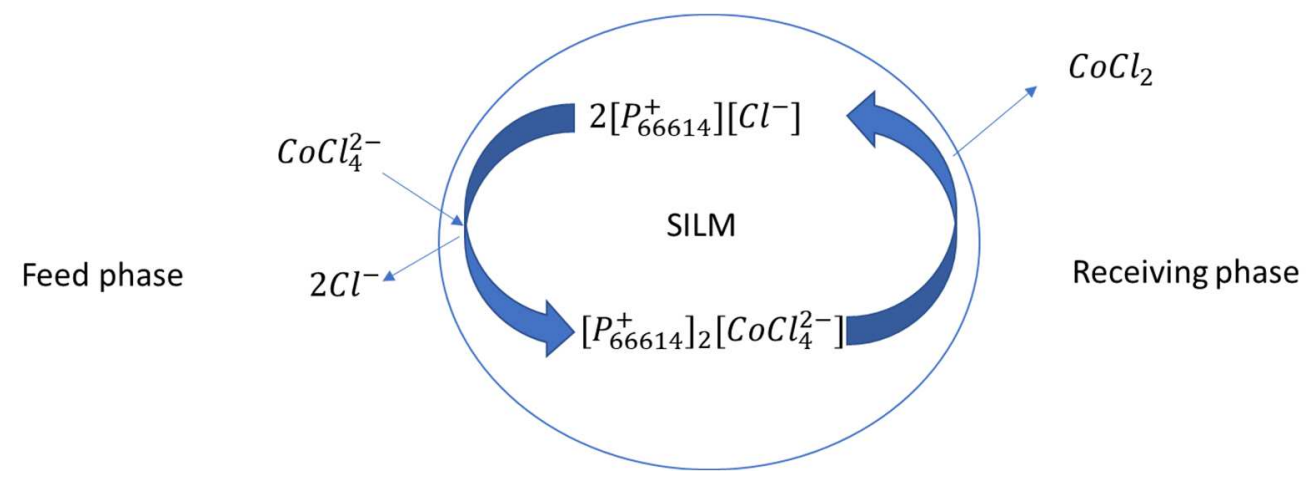

Figure 14. Proposed mechanism of cobalt transport across the supported liquid membrane

The $\mathrm{CoCl}_{4}{ }^{2-}$ complexes are extracted by the $\mathrm{IL}$ at the feed/liquid membrane interface and then back-extracted at the liquid/membrane/interface in a continuous process. It seems that that the facilitated transport of cobalt across the membrane is a solution diffusionmechanism, characterized by stable complexes [62]. The IL-cobalt complexes $\left(\left[P_{66614}^{+}\right]\left[\mathrm{CoCl}_{4}^{2-}\right]\right)$ migrates from the feed to the receiving phase, while the IL $\left(\left[P_{66614}^{+}\right]\left[\mathrm{Cl}^{-}\right]\right)$migrates through the membrane in the opposite direction. In this SILM system, it is clear that the high viscosity of the IL will slow down the diffusion of cobalt complexes. Therefore, could presume it seems that the system is governed by mass transfer rather than chemical reactions which are often considered as fast and no ratelimiting steps [63]. 
The transport of cobalt through designed SILM and its selective separation from nickel can be visually illustrated by the change of color of both aqueous phases over time (Figure 15).
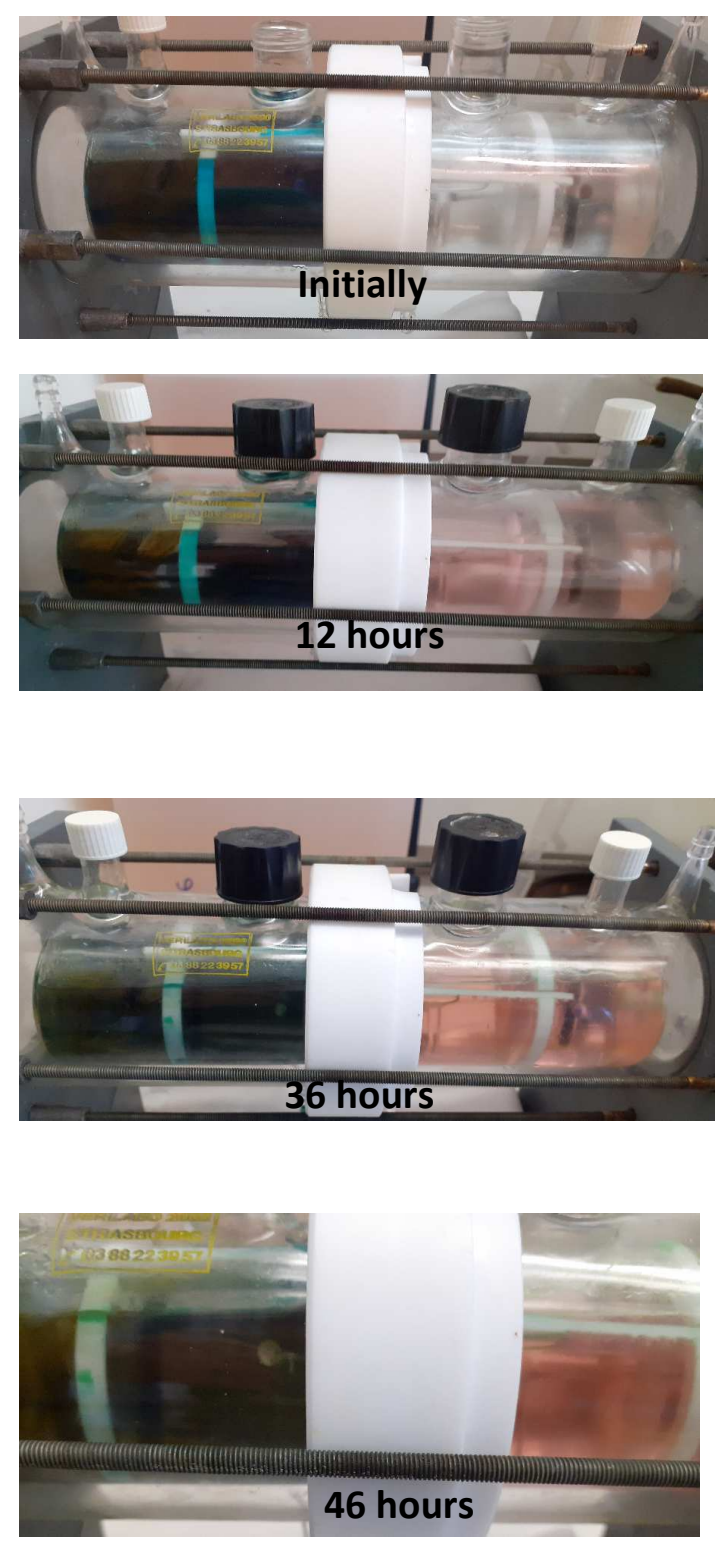

Figure 15. Picture of the membrane contactor initially and at various time intervals. Feed phase: $\mathrm{CoCl}_{2}\left(2000 \mathrm{mg} \cdot \mathrm{L}^{-1}\right)$ and $\mathrm{NiCl}_{2}\left(2000 \mathrm{mg} \cdot \mathrm{L}^{-1}\right)$ in $\mathrm{HCl}\left(9 \mathrm{~mol}^{-\mathrm{L}^{-1}}\right)$. Receiving phase: de-ionised water. Liquid membrane: $\left[\mathrm{P}_{66614}\right][\mathrm{Cl}]$ in hydrophilic PVDF.

At the start of the experiment, the aqueous feed phase (left) is blue due to the presence of the anionic cobalt species, while the receiving phase (water, right) has no color. After a few hours, the receiving phase turns to red due to the transfer of cobalt and its stripping under the form of the red $\mathrm{CoCl}_{2}$. With a longer time of contact, the red coloration of the receiving phase gets more and more pronounced. After 46 hours, the green color of the feed phase and the red color of the receiving phase indicates that nickel is left in the feed phase while cobalt is transported from the feed to the receiving phase. 
SILM stability was evaluated by using the same membrane over several cycles of extraction, using fresh feed and receiving phases for each cycle (Table 5).

Table 5. Amount of cobalt transported from the feed phase after several cycles with the same membranes Feed phase: $\mathrm{CoCl}_{2}\left(200 \mathrm{mg} \cdot \mathrm{L}^{-1}\right)$ in $\mathrm{HCl}\left(9\right.$ mol. $\left.\mathrm{L}^{-1}\right)$. Receiving phase: de-ionised water. Liquid membrane: $\left[\mathrm{P}_{66614}\right][\mathrm{Cl}]$ in hydrophilic PVDF.

\begin{tabular}{cccc}
\hline [Co], initially $\left(\mathrm{mg} . \mathrm{L}^{-1}\right)$ & Cycle & Time of the cycle (hours) & $\begin{array}{c}\text { Amount of Co in the } \\
\text { receiving phase }\end{array}$ \\
\hline 200 & 1 & 24 & $100 \pm 4 \%$ \\
200 & 2 & 24 & $100 \pm 3 \%$ \\
200 & 3 & 24 & $100 \pm 6 \%$
\end{tabular}

It can be seen from Table 5 that complete transport of cobalt was obtained, using the same liquid membrane over three consecutive cycles of 24 hours each. The IL is surely removed from the surface of the membrane after being immersed for a long period in water. However, the long alkyl chains of the IL lead to Van der Waals's interaction with the support [64], [65]. The higher capillary forces associated with the high viscosity of the IL make the liquid membrane highly stable and the IL difficult to be forced out of the pores.

\section{Conclusions}

Cobalt extraction was studied using a SILM based on the undiluted room-temperature hydrophobic IL $\left[\mathrm{P}_{66614}\right][\mathrm{Cl}]$. The effect of several parameters on cobalt sorption was studied under static conditions and it was evidenced that up to $86 \%$ of cobalt can be extracted with high selectivity over nickel. Cobalt can be stripped with deionized water, but the re-usability was not possible since the IL at the surface of the membrane is leached to the aqueous phase. However, this sorption technique is interesting for analytical purposes since it requires low volumes of organic reagents.

The SILM was used in a continuous mode with water as a receiving phase. The effect of the hydrophobic/hydrophobic nature of the polymer was studied. Cobalt stripping was not quantitative when using a hydrophobic polymer since water is not available to wash the excess chloride from the IL. However, hydrochloric acid transport was evidenced and could be attributed to the formation of micro-environments inside the SILM. This effect could be used to recover and purify acids from aqueous phases. Complete extraction and stripping of cobalt were obtained when using a hydrophilic polymer. The permeation ratio and metal ion flux of cobalt were both higher when using a hydrophilic polymer as compared to the hydrophobic one. The selectivity for cobalt over nickel was satisfying, but the water microenvironments were suspected to create non-selective paths for the transport of metals across the SILM. The designed SILM was proven to be stable over three cycles, allowing to obtain a complete transport of cobalt.

\section{Acknowledgments}

The financial support from the French Environment \& Energy Management Agency (Agence de l'Environnement et de la Maîtrise de l'Énergie, ADEME, Ph.D. fellowship to GZ) is 
gratefully acknowledged. The authors thank Dr A. Boos, P. Ronot and I. El-Masoudi (IPHC, France) for the ICP-OES analysis.

\section{References}

[1] G. Martin, L. Rentsch, M. Höck, M. Bertau, Lithium market research - global supply, future demand and price development, Energy Storage Materials. 6 (2017) 171-179. https://doi.org/10.1016/j.ensm.2016.11.004.

[2] E.A. Olivetti, G. Ceder, G.G. Gaustad, X. Fu, Lithium-Ion Battery Supply Chain Considerations: Analysis of Potential Bottlenecks in Critical Metals, Joule. 1 (2017) 229243. https://doi.org/10.1016/j.joule.2017.08.019.

[3] A. Tisserant, S. Pauliuk, Matching global cobalt demand under different scenarios for co-production and mining attractiveness, Economic Structures. 5 (2016) 4. https://doi.org/10.1186/s40008-016-0035-x.

[4] S. Deetman, S. Pauliuk, D.P. van Vuuren, E. van der Voet, A. Tukker, Scenarios for Demand Growth of Metals in Electricity Generation Technologies, Cars, and Electronic Appliances, Environ. Sci. Technol. $52 \quad$ (2018) 4950-4959. https://doi.org/10.1021/acs.est.7b05549.

[5] S. van den Brink, R. Kleijn, B. Sprecher, A. Tukker, Identifying supply risks by mapping the cobalt supply chain, Resources, Conservation and Recycling. 156 (2020) 104743. https://doi.org/10.1016/j.resconrec.2020.104743.

[6] K. Kongolo, M.D. Mwema, A.N. Banza, E. Gock, Cobalt and zinc recovery from copper sulphate solution by solvent extraction, Minerals Engineering. 16 (2003) 1371-1374. https://doi.org/10.1016/j.mineng.2003.09.001.

[7] J. Kang, G. Senanayake, J. Sohn, S.M. Shin, Recovery of cobalt sulfate from spent lithium ion batteries by reductive leaching and solvent extraction with Cyanex 272, Hydrometallurgy. $100 \quad$ (2010) 168-171. https://doi.org/10.1016/j.hydromet.2009.10.010.

[8] C.A. Nogueira, F. Delmas, New flowsheet for the recovery of cadmium, cobalt and nickel from spent $\mathrm{Ni}-\mathrm{Cd}$ batteries by solvent extraction, Hydrometallurgy. 52 (1999) 267-287. https://doi.org/10.1016/S0304-386X(99)00026-2.

[9] S. Dhiman, B. Gupta, Partition studies on cobalt and recycling of valuable metals from waste Li-ion batteries via solvent extraction and chemical precipitation, Journal of $\begin{array}{llll}\text { Cleaner } & \text { Production. } & 225 & \text { (2019) }\end{array}$ https://doi.org/10.1016/j.jclepro.2019.04.004.

[10] J. Flieger, M. Tatarczak-Michalewska, E. Blicharska, A. Madejska, W. Flieger, A. Adamczuk, Extraction of cobalt (II) using ionic liquid-based bi-phase and three-phase systems without adding any chelating agents with new recycling procedure, Separation $\begin{array}{lllll}\text { and } & \text { Purification } & \text { Technology. } & 209 & \text { (2019) }\end{array}$ https://doi.org/10.1016/j.seppur.2018.09.046.

[11] Z. Liu, J. Wu, X. Liu, W. Wang, Z. Li, R. Xu, Y. Ding, J. Wang, Recovery of neodymium, dysprosium, and cobalt from $\mathrm{NdFeB}$ magnet leachate using an unsymmetrical dialkylphosphinic acid extractant, INET-3, Journal of Rare Earths. (2020) S1002072119303734. https://doi.org/10.1016/j.jre.2020.01.018. 
[12] M. Orefice, H. Audoor, Z. Li, K. Binnemans, Solvometallurgical route for the recovery of $\mathrm{Sm}, \mathrm{Co}, \mathrm{Cu}$ and $\mathrm{Fe}$ from SmCo permanent magnets, Separation and Purification Technology. 219 (2019) 281-289. https://doi.org/10.1016/j.seppur.2019.03.029.

[13] S. Sobekova Foltova, T. Vander Hoogerstraete, D. Banerjee, K. Binnemans, Samarium/cobalt separation by solvent extraction with undiluted quaternary ammonium ionic liquids, Separation and Purification Technology. 210 (2019) 209-218. https://doi.org/10.1016/j.seppur.2018.07.069.

[14] S. Wang, C. Wang, F. Lai, F. Yan, Z. Zhang, Reduction-ammoniacal leaching to recycle lithium, cobalt, and nickel from spent lithium-ion batteries with a hydrothermal method: Effect of reductants and ammonium salts, Waste Management. 102 (2020) 122-130. https://doi.org/10.1016/j.wasman.2019.10.017.

[15] W.-Y. Wang, C.H. Yen, J.-L. Lin, R.-B. Xu, Recovery of high-purity metallic cobalt from lithium nickel manganese cobalt oxide (NMC)-type Li-ion battery, J Mater Cycles Waste Manag. 21 (2019) 300-307. https://doi.org/10.1007/s10163-018-0790-x.

[16] M. Soylak, M. Koksal, Deep eutectic solvent microextraction of lead(II), cobalt(II), nickel(II) and manganese(II) ions for the separation and preconcentration in some oil samples from Turkey prior to their microsampling flame atomic absorption spectrometric determination, Microchemical Journal. 147 (2019) 832-837. https://doi.org/10.1016/j.microc.2019.04.006.

[17] Z.A. Alothman, M.A. Habila, E. Yilmaz, N.M. Al-Harbi, M. Soylak, Supramolecular microextraction of cobalt from water samples before its microsampling flame atomic absorption spectrometric detection, International Journal of Environmental Analytical Chemistry. 95 (2015) 1311-1320. https://doi.org/10.1080/03067319.2015.1090568.

[18] E. Koosha, M. Ramezani, A. Niazi, Determination of cobalt by air-assisted liquid-liquid microextraction, Toxicological \& Environmental Chemistry. 100 (2018) 317-325. https://doi.org/10.1080/02772248.2018.1499916.

[19] M. Shirani, F. Salari, S. Habibollahi, A. Akbari, Needle hub in-syringe solid phase extraction based a novel functionalized biopolyamide for simultaneous green separation/preconcentration and determination of cobalt, nickel, and chromium (III) in food and environmental samples with micro sampling flame atomic absorption spectrometry, Microchemical Journal. $152 \quad$ (2020) 104340. https://doi.org/10.1016/j.microc.2019.104340.

[20] A.B. Botelho Junior, D.B. Dreisinger, D.C.R. Espinosa, A Review of Nickel, Copper, and Cobalt Recovery by Chelating Ion Exchange Resins from Mining Processes and Mining Tailings, Mining, Metallurgy \& Exploration. $36 \quad$ (2019) 199-213. https://doi.org/10.1007/s42461-018-0016-8.

[21] J.J. Eksteen, E.A. Oraby, V. Nguyen, Leaching and ion exchange based recovery of nickel and cobalt from a low grade, serpentine-rich sulfide ore using an alkaline glycine lixiviant system, Minerals Engineering. $145 \quad$ (2020) 106073. https://doi.org/10.1016/j.mineng.2019.106073.

[22] L. Rosato, G.B. Harris, R.W. Stanley, Separation of nickel from cobalt in sulphate medium by ion exchange, Hydrometallurgy. 13 (1984) 33-44. https://doi.org/10.1016/0304-386X(84)90015-X. 
[23] A. Chagnes, Simulation of Solvent Extraction Flowsheets by a Global Model Combining Physicochemical and Engineering Approaches-Application to Cobalt(II) Extraction by D2EHPA, Solvent Extraction and Ion Exchange. 38 (2020) 3-13. https://doi.org/10.1080/07366299.2019.1691135.

[24] W.A. Rickelton, D.S. Flett, D.W. West, COBALT-NICKEL SEPARATION BY SOLVENT EXTRACTION WITH BIS(2,4,4 TRIMETHYLPENTYL)PHOSPHINIC ACID, Solvent Extraction and Ion Exchange. 2 (1984) 815-838. https://doi.org/10.1080/07366298408918476.

[25] J.S. Preston, Solvent extraction of cobalt and nickel by organophosphorus acids I. Comparison of phosphoric, phosphonic and phosphonic acid systems, Hydrometallurgy. 9 (1982) 115-133. https://doi.org/10.1016/0304-386X(82)90012-3.

[26] M.L. Good, S.E. Bryan, Extraction of group VIII metals by long chain alkyl amines-II, Journal of Inorganic and Nuclear Chemistry. 20 (1961) 140-146. https://doi.org/10.1016/0022-1902(61)80471-5.

[27] M. Filiz, N.A. Sayar, A.A. Sayar, Extraction of cobalt(II) from aqueous hydrochloric acid solutions into alamine 336-m-xylene mixtures, Hydrometallurgy. 81 (2006) 167-173. https://doi.org/10.1016/j.hydromet.2005.12.007.

[28] R. Torkaman, M. Asadollahzadeh, M. Torab-Mostaedi, M. Ghanadi Maragheh, Recovery of cobalt from spent lithium ion batteries by using acidic and basic extractants in solvent extraction process, Separation and Purification Technology. 186 (2017) 318325. https://doi.org/10.1016/j.seppur.2017.06.023.

[29] S. Riaño, M. Petranikova, B. Onghena, T. Vander Hoogerstraete, D. Banerjee, M.R.StJ. Foreman, C. Ekberg, K. Binnemans, Separation of rare earths and other valuable metals from deep-eutectic solvents: a new alternative for the recycling of used NdFeB magnets, RSC Adv. 7 (2017) 32100-32113. https://doi.org/10.1039/C7RA06540J.

[30] S. Wellens, B. Thijs, K. Binnemans, An environmentally friendlier approach to hydrometallurgy: highly selective separation of cobalt from nickel by solvent extraction with undiluted phosphonium ionic liquids, Green Chem. 14 (2012) 1657. https://doi.org/10.1039/c2gc35246j.

[31] B. Onghena, S. Valgaeren, T. Vander Hoogerstraete, K. Binnemans, Cobalt( II )/nickel( II ) separation from sulfate media by solvent extraction with an undiluted quaternary phosphonium ionic liquid, RSC Adv. 7 (2017) 35992-35999. https://doi.org/10.1039/C7RA04753C.

[32] S.P.F. Costa, V.D. Justina, K. Bica, M. Vasiloiu, P.C.A.G. Pinto, M.L.M.F.S. Saraiva, Automated evaluation of pharmaceutically active ionic liquids' (eco)toxicity through the inhibition of human carboxylesterase and Vibrio fischeri, Journal of Hazardous Materials. 265 (2014) 133-141. https://doi.org/10.1016/j.jhazmat.2013.11.052.

[33] K.S. Egorova, V.P. Ananikov, Toxicity of Ionic Liquids: Eco(cyto)activity as Complicated, but Unavoidable Parameter for Task-Specific Optimization, ChemSusChem. 7 (2014) 336-360. https://doi.org/10.1002/cssc.201300459.

[34] S.P.M. Ventura, C.S. Marques, A.A. Rosatella, C.A.M. Afonso, F. Gonçalves, J.A.P. Coutinho, Toxicity assessment of various ionic liquid families towards Vibrio fischeri marine bacteria, Ecotoxicology and Environmental Safety. 76 (2012) 162-168. https://doi.org/10.1016/j.ecoenv.2011.10.006. 
[35] D. Dupont, D. Depuydt, K. Binnemans, Overview of the Effect of Salts on Biphasic Ionic Liquid/Water Solvent Extraction Systems: Anion Exchange, Mutual Solubility, and Thermomorphic Properties, J. Phys. Chem. B. 119 (2015) 6747-6757. https://doi.org/10.1021/acs.jpcb.5b02980.

[36] J.D. Holbrey, K.R. Seddon, Ionic Liquids, Clean Technologies and Environmental Policy. 1 (1999) 223-236. https://doi.org/10.1007/s100980050036.

[37] N. Schaeffer, H. Passos, I. Billard, N. Papaiconomou, J.A.P. Coutinho, Recovery of metals from waste electrical and electronic equipment (WEEE) using unconventional solvents based on ionic liquids, Critical Reviews in Environmental Science and Technology. 48 (2018) 859-922. https://doi.org/10.1080/10643389.2018.1477417.

[38] R.N. Raja Sulaiman, N. Othman, N.F. Mohamed Noah, N. Jusoh, Removal of nickel from industrial effluent using a synergistic mixtures of acidic and solvating carriers in palm oil-based diluent via supported liquid membrane process, Chemical Engineering $\begin{array}{lllll}\text { Research and } 137 & \text { (2018) 360-375. }\end{array}$ https://doi.org/10.1016/j.cherd.2018.07.034.

[39] R.N.R. Sulaiman, N. Jusoh, N. Othman, N.F.M. Noah, M.B. Rosly, H.A. Rahman, Supported liquid membrane extraction of nickel using stable composite SPEEK/PVDF support impregnated with a sustainable liquid membrane, Journal of Hazardous Materials. 380 (2019) 120895. https://doi.org/10.1016/j.jhazmat.2019.120895.

[40] D. Hopkinson, M. Zeh, D. Luebke, The bubble point of supported ionic liquid membranes using flat sheet supports, Journal of Membrane Science. 468 (2014) 155162. https://doi.org/10.1016/j.memsci.2014.05.042.

[41] A.P. de los Ríos, F.J. Hernández-Fernández, L.J. Lozano, S. Sánchez-Segado, A. GinestáAnzola, C. Godínez, F. Tomás-Alonso, J. Quesada-Medina, On the selective separation of metal ions from hydrochloride aqueous solution by pertraction through supported ionic liquid membranes, Journal of Membrane Science. 444 (2013) 469-481. https://doi.org/10.1016/j.memsci.2013.05.006.

[42] E. Jean, D. Villemin, M. Hlaibi, L. Lebrun, Heavy metal ions extraction using new supported liquid membranes containing ionic liquid as carrier, Separation and Purification Technology. 201 (2018) 1-9. https://doi.org/10.1016/j.seppur.2018.02.033.

[43] S. Wellens, T. Vander Hoogerstraete, C. Möller, B. Thijs, J. Luyten, K. Binnemans, Dissolution of metal oxides in an acid-saturated ionic liquid solution and investigation of the back-extraction behaviour to the aqueous phase, Hydrometallurgy. 144-145 (2014) 27-33. https://doi.org/10.1016/j.hydromet.2014.01.015.

[44] O.U. Ahmed, F.S. Mjalli, A.M. Gujarathi, T. Al-Wahaibi, Y. Al-Wahaibi, I.M. AlNashef, Feasibility of phosphonium-based ionic liquids as solvents for extractive desulfurization of liquid fuels, Fluid Phase Equilibria. 401 (2015) 102-109. https://doi.org/10.1016/j.fluid.2015.05.015.

[45] M. Tariq, M.G. Freire, B. Saramago, J.A.P. Coutinho, J.N.C. Lopes, L.P.N. Rebelo, Surface tension of ionic liquids and ionic liquid solutions, Chem. Soc. Rev. 41 (2012) 829-868. https://doi.org/10.1039/C1CS15146K.

[46] C.M.S.S. Neves, P.J. Carvalho, M.G. Freire, J.A.P. Coutinho, Thermophysical properties of pure and water-saturated tetradecyltrihexylphosphonium-based ionic liquids, The 
Journal of Chemical Thermodynamics. $43 \quad$ (2011) 948-957. https://doi.org/10.1016/j.jct.2011.01.016.

[47] F. Liu, N.A. Hashim, Y. Liu, M.R.M. Abed, K. Li, Progress in the production and modification of PVDF membranes, Journal of Membrane Science. 375 (2011) 1-27. https://doi.org/10.1016/j.memsci.2011.03.014.

[48] G. Zante, M. Boltoeva, A. Masmoudi, R. Barillon, D. Trébouet, Lithium extraction from complex aqueous solutions using supported ionic liquid membranes, Journal of Membrane Science. 580 (2019) 62-76. https://doi.org/10.1016/j.memsci.2019.03.013.

[49] P.R. Danesi, Separation of Metal Species by Supported Liquid Membranes, Separation $\begin{array}{lllll}\text { Science } \quad \text { and } & \text { Technology. } & 19 & \text { (1984) }\end{array}$ https://doi.org/10.1080/01496398408068598.

[50] C. Cai, F. Yang, Z. Zhao, Q. Liao, R. Bai, W. Guo, P. Chen, Y. Zhang, H. Zhang, Promising transport and high-selective separation of $\mathrm{Li}(\mathrm{I})$ from $\mathrm{Na}(\mathrm{I})$ and $\mathrm{K}(\mathrm{I})$ by a functional polymer inclusion membrane (PIM) system, Journal of Membrane Science. 579 (2019) 1-10. https://doi.org/10.1016/j.memsci.2019.02.046.

[51] F.J. Hernández-Fernández, A.P. de los Ríos, F. Tomás-Alonso, J.M. Palacios, G. Víllora, Preparation of supported ionic liquid membranes: Influence of the ionic liquid immobilization method on their operational stability, Journal of Membrane Science. 341 (2009) 172-177. https://doi.org/10.1016/j.memsci.2009.06.003.

[52] B. Pospiech, W. Walkowiak, Separation of copper(II), cobalt(II) and nickel(II) from chloride solutions by polymer inclusion membranes, Separation and Purification Technology. 57 (2007) 461-465. https://doi.org/10.1016/j.seppur.2006.07.005.

[53] S. Kagaya, R.W. Cattrall, S.D. Kolev, Solid-Phase Extraction of Cobalt(II) from Lithium Chloride Solutions Using a Poly(vinyl chloride)-based Polymer Inclusion Membrane with Aliquat 336 as the Carrier, Anal. Sci. $27 \quad$ (2011) 653. https://doi.org/10.2116/analsci.27.653.

[54] L.J. Lozano, C. Godínez, A.P. de los Ríos, F.J. Hernández-Fernández, S. Sánchez-Segado, F.J. Alguacil, Recent advances in supported ionic liquid membrane technology, Journal of Membrane Science. $376 \quad$ (2011) 1-14. https://doi.org/10.1016/j.memsci.2011.03.036.

[55] J. Ji, W.C. Cooper, Nickel speciation in aqueous chloride solutions, Electrochimica Acta. 41 (1996) 1549-1560. https://doi.org/10.1016/0013-4686(95)00407-6.

[56] R. Fortunato, C.A.M. Afonso, M.A.M. Reis, J.G. Crespo, Supported liquid membranes using ionic liquids: study of stability and transport mechanisms, Journal of Membrane Science. 242 (2004) 197-209. https://doi.org/10.1016/j.memsci.2003.07.028.

[57] S. Lan, X. Wen, Z. Zhu, F. Shao, C. Zhu, Recycling of spent nitric acid solution from electrodialysis by diffusion dialysis, Desalination. 278 (2011) 227-230. https://doi.org/10.1016/j.desal.2011.05.031.

[58] S.H. Lin, M.C. Lo, Recovery of sulfuric acid from waste aluminum surface processing solution by diffusion dialysis, Journal of Hazardous Materials. 60 (1998) 247-257. https://doi.org/10.1016/S0304-3894(98)00099-5. 
[59] M.F. San Román, I. Ortiz Gándara, R. Ibañez, I. Ortiz, Hybrid membrane process for the recovery of major components (zinc, iron and $\mathrm{HCl}$ ) from spent pickling effluents, Journal of Membrane Science. 415-416 (2012) 616-623. https://doi.org/10.1016/j.memsci.2012.05.063.

[60] K. Song, Q. Meng, F. Shu, Z. Ye, Recovery of high purity sulfuric acid from the waste acid in toluene nitration process by rectification, Chemosphere. 90 (2013) 1558-1562. https://doi.org/10.1016/j.chemosphere.2012.09.043.

[61] J. Xu, S. Lu, D. Fu, Recovery of hydrochloric acid from the waste acid solution by diffusion dialysis, Journal of Hazardous Materials. 165 (2009) 832-837. https://doi.org/10.1016/j.jhazmat.2008.10.064.

[62] K. Touaj, N. Tbeur, M. Hor, J.-F. Verchère, M. Hlaïbi, A supported liquid membrane (SLM) with resorcinarene for facilitated transport of methyl glycopyranosides: Parameters and mechanism relating to the transport, Journal of Membrane Science. 337 (2009) 28-38. https://doi.org/10.1016/j.memsci.2009.03.014.

[63] O.N. Ata, S. Çolak, Modelling of zinc transport through a supported liquid membrane, Hydrometallurgy. 80 (2005) 155-162. https://doi.org/10.1016/j.hydromet.2005.06.008.

[64] J. Wang, J. Luo, S. Feng, H. Li, Y. Wan, X. Zhang, Recent development of ionic liquid membranes, Green Energy \& Environment. 1 (2016) 43-61. https://doi.org/10.1016/j.gee.2016.05.002.

[65] V.S. Kislik, ed., Liquid membranes: principles and applications in chemical separations and wastewater treatment, 1. ed, Elsevier, Amsterdam, 2010. 


\section{Graphical Abstract}

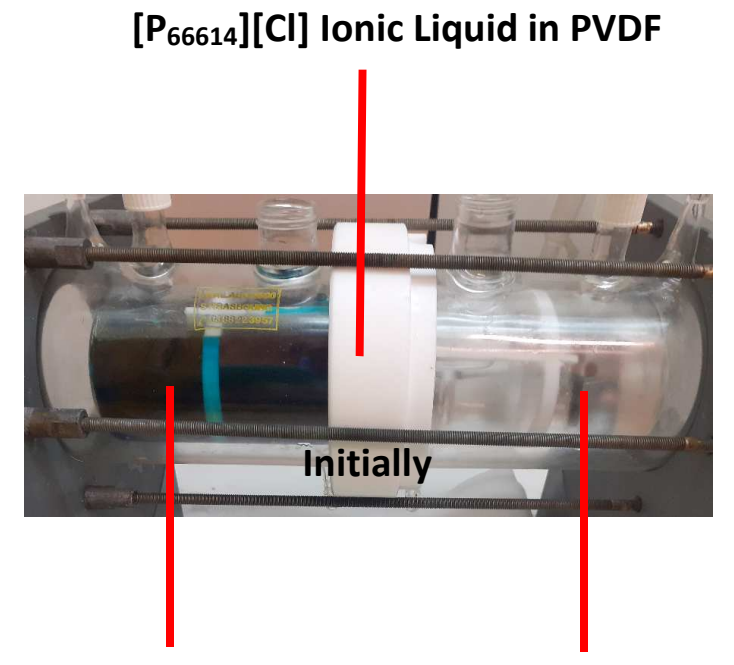

$\mathrm{Co}+\mathrm{Ni}$

$\mathrm{H}_{2} \mathrm{O}$

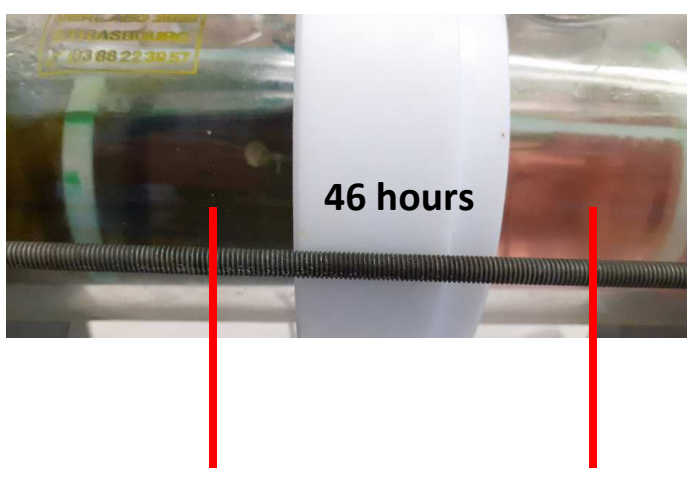

Ni

Co 